\title{
Unconstrained Design: Improving Multitasking with In-Vehicle Information Systems through Enhanced Situation Awareness
}

Journal: Theoretical Issues in Ergonomics Science

Lee Skrypchuk $^{\mathrm{ab}}$, Pat Langdon ${ }^{\mathrm{b}}$, Ben D. Sawyer ${ }^{\mathrm{c}}$, P. John Clarkson ${ }^{\mathrm{b}}$

${ }^{a}$ Research and Technology Department, Jaguar Land Rover, Coventry, United Kingdom

${ }^{b}$ Engineering Design Centre, Cambridge University. Cambridge, United Kingdom

${ }^{c}$ Department of Industrial Engineering and Management Systems, University of Central Florida. Orlando, United States.

\begin{abstract}
In the age of information, in-vehicle multitasking is inevitable. The popularity of the automobile in combination with the demands of everyday life presents a demand to do more than simply focus on the road. Situation Awareness (SA) is a theory that allows designers to understand how operators interact in dynamic, complex environments. Unconstrained Design is proposed as a way of enhancing multitasking performance in-vehicle. This paper presents an experimental investigation into human-machine interface concepts that aim to support drivers to multitask in-vehicle when frequent task switching is required. Two SA-based approaches were investigated, one which focussed on supporting preparation for a Non-Driving Related Activity (NDRA), and one which focussed on supporting the Driving Related Activity (DRA) when an NDRA is active. While multitasking, Contextual Cueing, using a Head-up Display, produced significant reductions in NDRA response time while an auditory lane keeping aid increased the amount of time a driver spent in the central region of a lane. This provides evidence to suggest that using SA and Unconstrained Design as a philosophy for the design of IVIS that supports drivers' ability to multitask in-vehicle, could lead to task performance improvements.
\end{abstract}

\section{Keywords}

Automotive, Human Machine Interface, Situation Awareness, Multitasking, Driver Behaviour

Word Count: 9869 
Relevance to human factors / ergonomics theory - The present work is relevant for this journal because it directly addresses issues associated with characterisations of awareness in relation to the vehicle environment, this is a topic central to human factors and ergonomic theory. It proposes using an IVIS design approach that addresses increasing demand within the vehicle by taking an unrestrained approach to the problem. Evidence is found to suggest that the approach provides benefits in designing IVIS that enhance driver awareness, thus providing a novel approach to solving an existing problem 


\section{Introduction}

The motor vehicle is a necessity of modern life. Its popularity saw over 70 million vehicle sales in 2017 worldwide making it the most popular mode of personal transportation (International Transport Forum, 2017; OICA, 2018). Vehicle technology is progressing rapidly, best advertised by the prediction that one in five cars will be connected to the internet by 2020 (Mohr et al., 2013). This level of connectivity creates expectations of smartphonelike functionality, meaning that the propensity of information gathering seen in everyday life is spreading to the car (Regan et al., 2008; Sanbonmatsu et al., 2013). The result is conflict in an already demanding situation, increasing the responsibility of the vehicle manufacturer to make sure that this complexity is managed appropriately.

The current era of modern humanity is known as the Information Age best embodied by the ubiquitous mobile device, providing 24/7 access to information and media (Castells, 1997). This has shaped new societal behaviours such as Media Multitasking, defined as the ability to divide attention between multiple sources of media (Lang and Chrzan, 2015). There is increasing evidence to suggest that people are becoming proficient at concurrent multitasking as users are often dissatisfied when focussing on a single task (Sanbonmatsu et al., 2013; Yap and Lim, 2013). One consequence is a syndrome called the Fear of Missing Out (FOMO), defined as:

“...a pervasive apprehension that others might be having rewarding experiences from which one is absent." (Przybylski et al., 2013, p. 1841).

A societal desire to constantly want to consume information and be more productive means it is inevitable that behaviour of this kind will spread, not least of all to the vehicle. This shift may be a cause for concern for vehicle safety, as inattention is one of the leading causes of human error in the vehicle (Regan et al., 2011). 


\section{Approaches to Addressing Increasing In-Vehicle Demand}

Constrained Design, Vehicle Automation, and Unconstrained Design are three key engineering-based approaches to address increasing in-vehicle demand, toward the goal of increasing safety (Figure 1).

Constrained Design involves reducing what is possible on the move, with the goal of restricting Non-Driving Related Activities (NDRAs) and forcing users to focus upon Driving Related Activity (DRA, see Burghardt et al., 2017; Lee, 2018; Litman, 2014). Constrained Design is often undertaken due to guidelines, legislated or voluntary, providing goals for how In-Vehicle Information Systems (IVIS) should operate (Driver Focus-Telematics Working Group, 2003; European Commission, 2006; JAMA, 2004; NHTSA, 2014; OICA, 2015). Attempting to increase safety by Constrained Design may result in frustrated users who simply revert to accessing functionality on portable devices not designed for use while driving, thus leading to a paradox for vehicle manufacturers. While in many countries these devices are currently illegal to use while driving, research suggests actual compliance is low

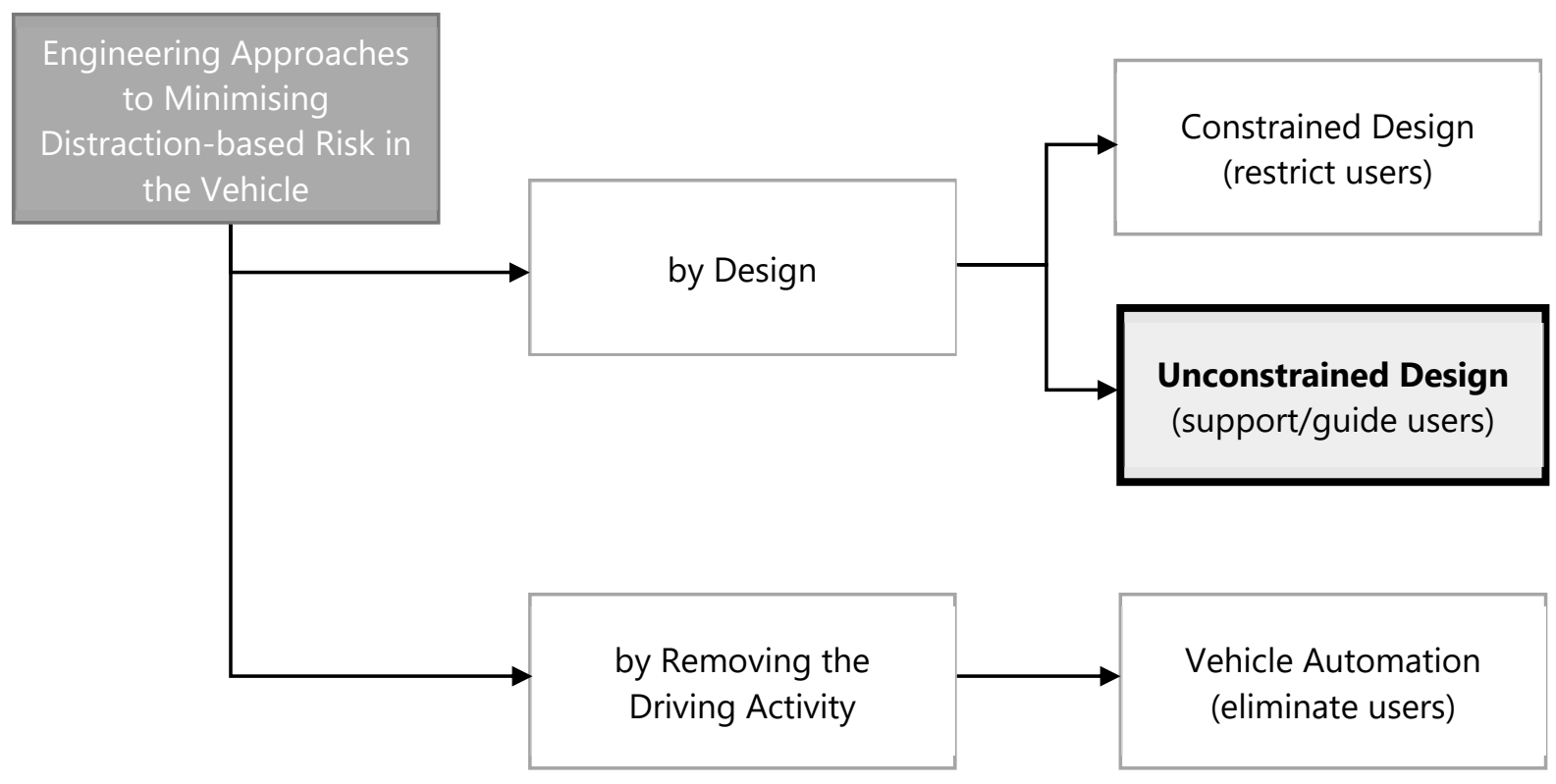

Figure 1 - Engineering-based approaches to dealing with additional in-vehicle complexity. 
(Rudisill and Zhu, 2016). As such, while Constrained Design can indeed reduce what a user might use an IVIS for, this may well force a user to complete the task anyway using an inappropriate device, and thus, users may perceive a safety decrease.

Vehicle Automation is another approach to addressing demand within vehicles, toward increased safety (Figure 1). As Vehicle Automation increases the DRA reduces, with highly automated vehicles potentially removing the driver completely from the driving task (SAE International, 2018). As an engineering remedy for distraction, a number of challenges face the present and future viability of vehicle automation. First, it may take time for automation technologies to reach a level where drivers can potentially disengage from the DRA. A driver's level of disengagement defines how well they will be able to engage in NDRAs. This leads to a second challenge. Higher levels of automation, in fact, free drivers to engage in NDRAs and increase distraction from what remains of the DRA. Indeed, as automated driving moves closer to removing the human from the driving task, it potentially causes more distraction and disengagement from what DRA remains (Greenlee et al., 2018).

Unconstrained Design is an alternative to Constrained Design or Vehicle Automation that considers the inherent distraction trade-offs between DRA and NDRAs. Evidence suggests that the NDRAs are varied with talking, eating, drinking, and checking mobile devices just a few examples (Parnell et al., 2018). Mind-wandering is also considered a type of NDRA that can happen during periods of low driving task demand (Yanko and Spalek, 2014). The potential consequence of overload (from multitasking) or underload (from monotony) is increased risk because of the need to balance the DRA with competing goals. Consequently, a proactive approach, Unconstrained Design, allowing drivers to complete certain activities using IVIS could facilitate in-vehicle multitasking and potentially increase customer satisfaction (Figure 1). Systems would need to be designed sympathetically, so as not to 
inhibit the driver's ability to maintain awareness of the DRA. Skrypchuk et al., (2018) propose the use of Situation Awareness (SA) as a way of designing systems that move away from restricting the ability to operate through Constrained Design, towards providing autonomy to operate in a safe and situationally aware manner through Unconstrained Design. The potential incentive for the vehicle manufacturer is increased customer satisfaction while reducing the impact of the Fear of Missing Out. This paper builds upon the theoretical approach taken in (Skrypchuk et al., 2019) to develop and evaluate IVIS that aim to improve task performance during an in-vehicle multitasking situation.

\section{Unconstrained Design: A Situation Awareness based Approach to In-Vehicle Multitasking}

The key feature proposed by Skrypchuk et al., (2018) is recognition that NDRAs are part of the construct of SA and therefore helps to explain how a driver manages two competing tasks together (Figure 2). The discourse proposes that separate knowledge structures support invehicle multitasking and is why task switching takes additional time, i.e. to allow the Situation Model for each activity to be accessed and maintained. Attention is therefore of central importance to a successful outcome. Consequently, by obtaining a deeper understanding of attentional shifts and the knowledge developed over time, IVIS that support the driver during highly demanding situations can be created.

\section{An Approach to Unconstrained Design}

To understand in-vehicle multitasking it is important to break it down into greater detail.

Taking insight from the Task Switching literature, a more detailed operational model of invehicle multitasking can be proposed (Altmann and Trafton, 2002; Monsell, 2003; St. John and Smallman, 2008). This model is NDRA type agnostic and shows the stages a driver goes 


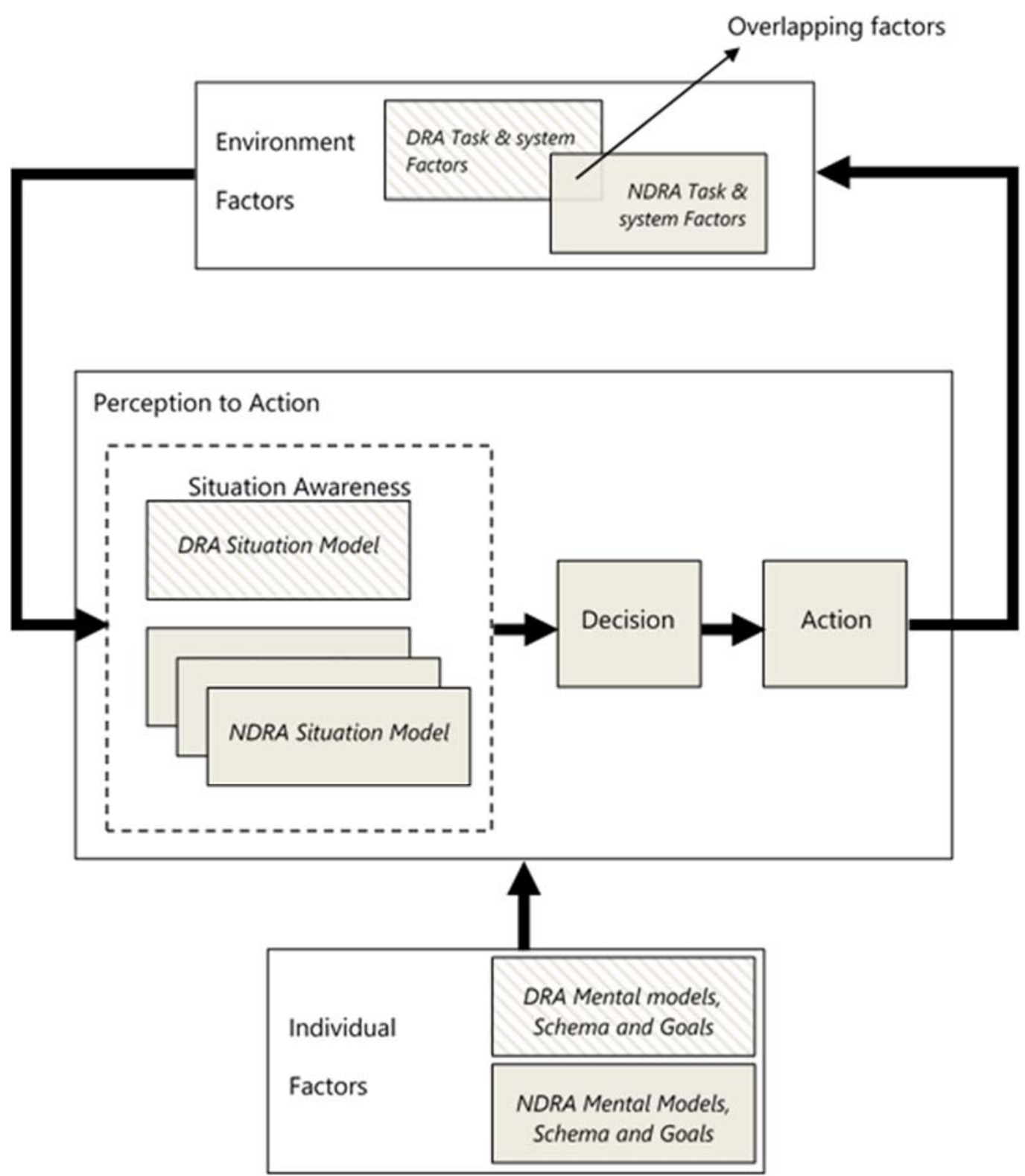

Figure 2 - Theoretical approach to SA for multitasking in the vehicle, adapted from Skrypchuk et al., (2018)

through when multitasking (Figure 3). There are three stages within this model:

1. Single Task: Pre and Post multitasking (Figure 3, Column A \& E)

2. Transition: from single to multitask and vice-versa (Figure 3, column B \& D)

3. Multitasking: The act of multitasking (Figure 3, Column C)

The scenario starts when the driver is solely focussed on the DRA, during which time the 


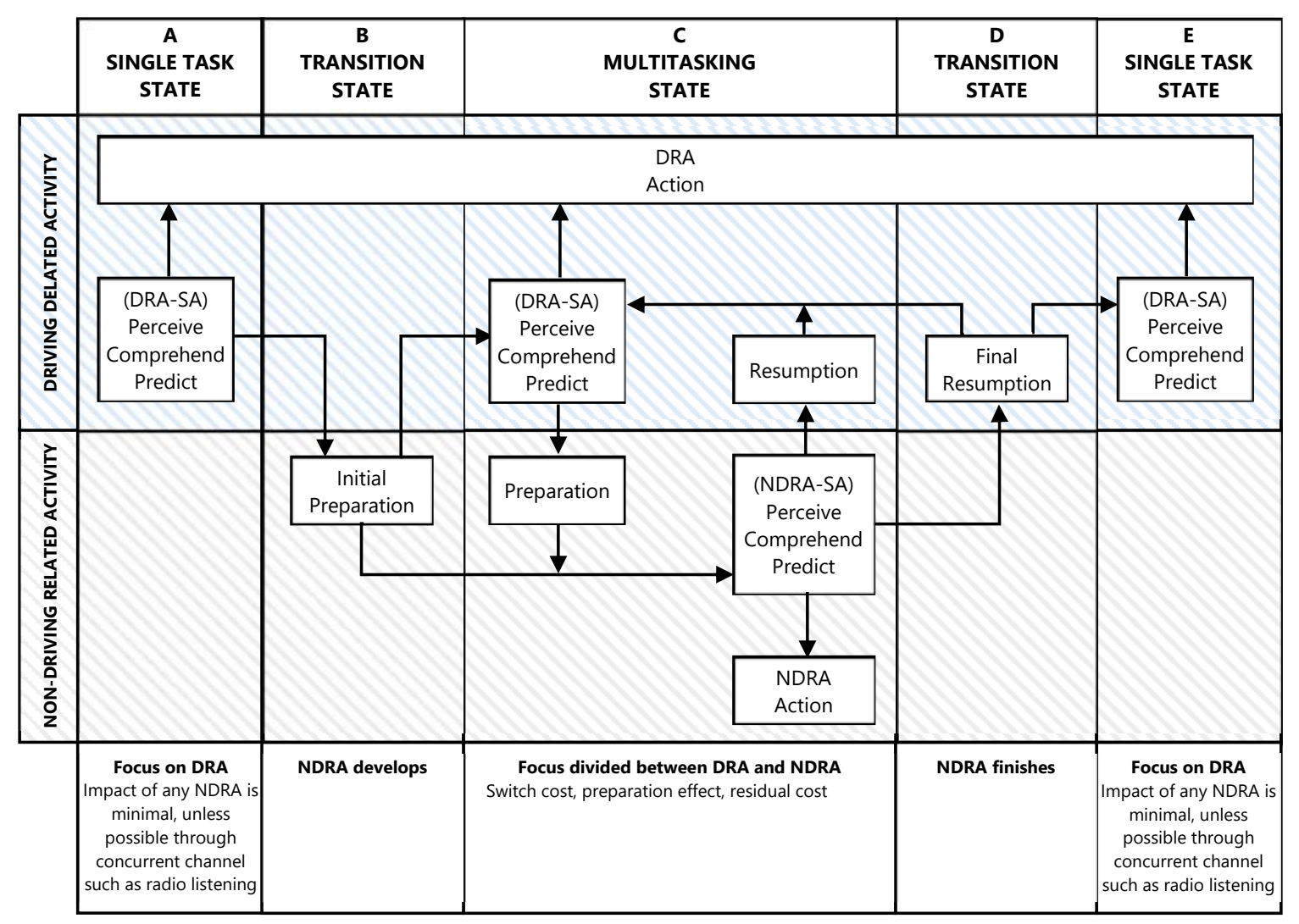

Figure 3 - Generic task-switching model for in-vehicle multitasking

motivation to multitask develops (Column A). The Transition State is where the driver starts to think about the NDRA including preparation for the task. This may result in the driver actively pursuing the NDRA or continuing with the DRA until ready. During the Multitasking Phase, the driver will attempt to balance the concurrent but competing activities. This phase is cyclic, reflecting the continuous shift between the two activities until the NDRA is complete (Altmann and Trafton, 2002; Gartenberg et al., 2014). The cyclic nature links the two Situation Models from Figure 2 meaning that the act of Situation Assessment supports both activities. This may involve times when the driver balances the needs of the DRA with the needs of the NDRA, such as scanning for NDRA information but not acting upon it. This preparation can help reduce the impact of task switching (Altmann, 2004; Monsell, 2003). 


\section{Where can Unconstrained Design Support Situation Awareness?}

When completely focussed on the DRA, drivers do not require all of their cognitive resources (Hancock et al., 2003; Kircher and Ahlstrom, 2017). During this time the motivation to multitask develops, possibly down to an absence of demand in the DRA (Angell et al., 2015). With this in mind, one critical aspect of the vehicle that may be missing is support to prepare for an NDRA (Altmann, 2004; St. John and Smallman, 2008). Any assistance in achieving this prior to multitasking should, in theory, support a driver to build awareness of an NDRA and potentially help when switching to the task. This type of information may also be useful during the Multitasking Phase to keep the driver aware of the current state of the NDRA when switching to and from the DRA. When multitasking, it is important to keep the Situation Model of an activity accurate and up to date, even if it is challenged by a competing task, otherwise task duration may be elongated. This provision of information introduces the concept of Cognitive Cueing defined as:

“...the commonplace fact that the occurrence of one cognitive event may instigate ("cue") the occurrence of another cognitive event...." (Gordon \& Flavell, 1977),

$$
\text { p. 1027). }
$$

The Contextual Cue, a similar concept, suggests that visual search can be reduced by the provision of supporting information (Chun, 2000). Providing information to cue the driver to keep awareness high acts as a form of human associative memory (Polson et al., 1975). This means that a driver can be kept aware of the operational aspects of an environment, even if a competing activity is being pursued. Therefore, presenting NDRA information to support the driver will be known as Approach 1.

Looking deeper into the Multitasking State, Figure 3 describes the process of task switching in an automotive context. If not supported otherwise, the driver is left to make decisions 
about when to switch based upon existing knowledge, whether accurate or not, developed through reinforcement learning. An experienced driver will determine a strategy by using information schema to estimate the time required to complete it (Finley et al., 2014). This may be in one go, or as is typical in the vehicle using a series of chunks (Brumby et al., 2007). Balancing the two activities requires both skill and metacognition to allow for an efficient interaction to take place (Gordon and Flavell, 1977; Rasmussen, 1983). DRA performance will suffer because of overly sharing resources with an active NDRA, leading to a weaker DRA Situation Model. Therefore, providing additional DRA information whilst an NDRA is active could counteract this effect, meaning DRA awareness could be maintained. This will be known as Approach 2.

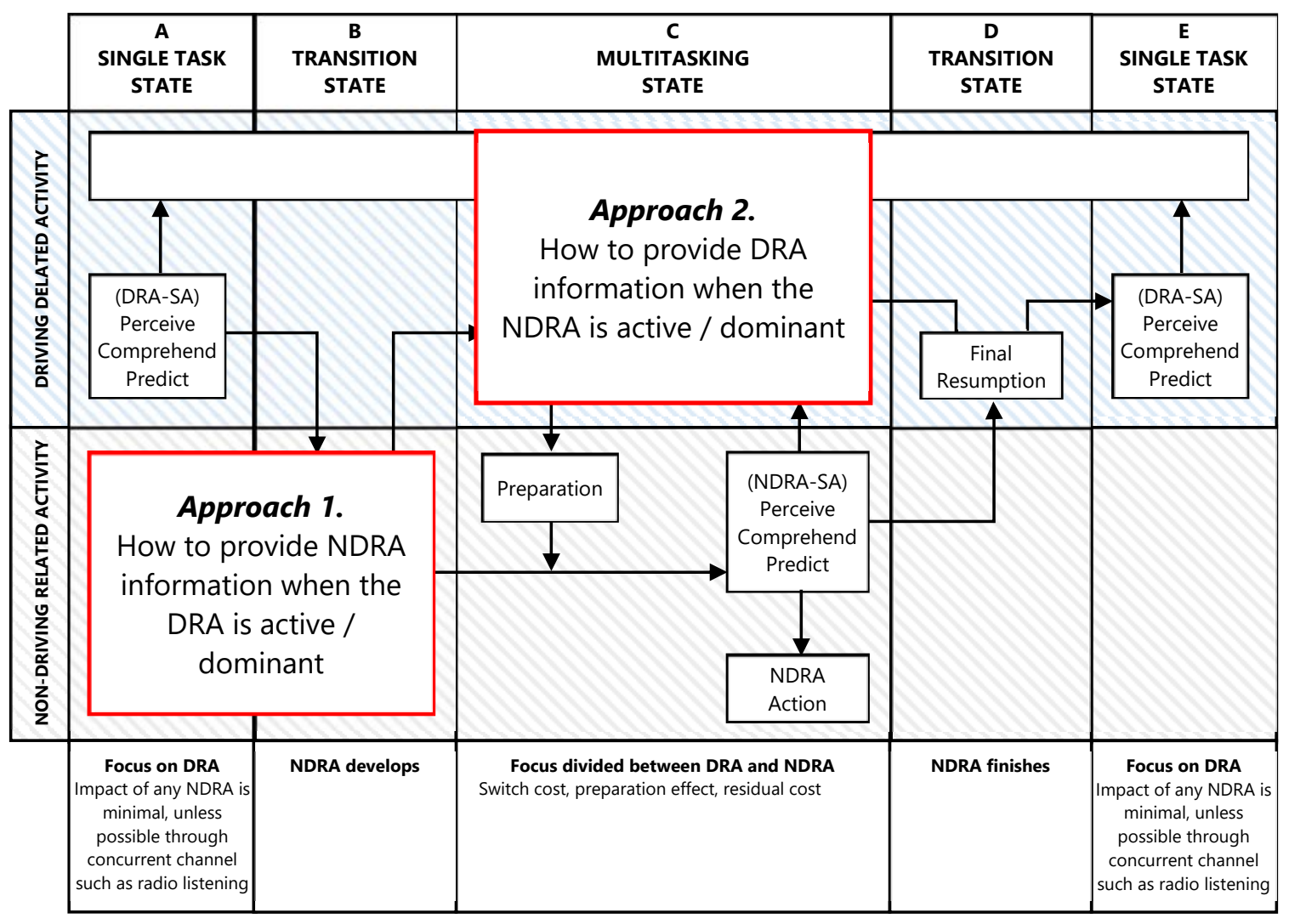

Figure 4 - Generic task switching model for in-vehicle multitasking - opportunities for SA-based design 
To summarise, in Figure 4, Approach 1 and Approach 2 emerge. These aim to support driver awareness in a multitasking situation. It is proposed that by providing additional information to support SA during the act of multitasking for a specific activity, these approaches could deliver IVIS that improve overall task performance. However, care will be needed to avoid issues such as information overload, error or distraction (Regan et al., 2011). The next section looks at SA-based design principles and defines concepts for the two approaches identified.

\section{Approach 1 - Conceptual Considerations}

The aim of Approach 1 is to present contextual information such that a driver can use it to help prepare for multitasking. As this research is focussed on how to improve embedded invehicle devices, the focus will be on NDRAs that a driver can typically carry out using the on-board information systems, such as media selection or hands-free phone functionality. Figure 5 (upper left) shows how a modern-day vehicle dashboard is typically laid out. DRAbased information is largely real-world and head-up, while NDRA information is virtualworld ${ }^{1}$ and head down. This means that unless the driver has explicit memory of the current state of the NDRA, they will need to look away from the road to understand it. A glance away from the road has the consequence of reducing the amount of DRA information perceived because the two activities require separate visual resources (Wickens and Liu, 1988). Therefore, one method of mitigation would be to present information collocated close to the driving scene to speed up preparation and make NDRA information more accessible. Importantly, this principle may conflict with one of the SA-based design rules which proposes to "organise information around goals" (Endsley et al., 2003) or the "law of proximity" (Wickens, 1993). In an automotive context, functionality is generally distributed

\footnotetext{
${ }^{1}$ By virtual we mean that the environment is created by a computing system which is not visible to the driver other than through the in-vehicle interface.
} 


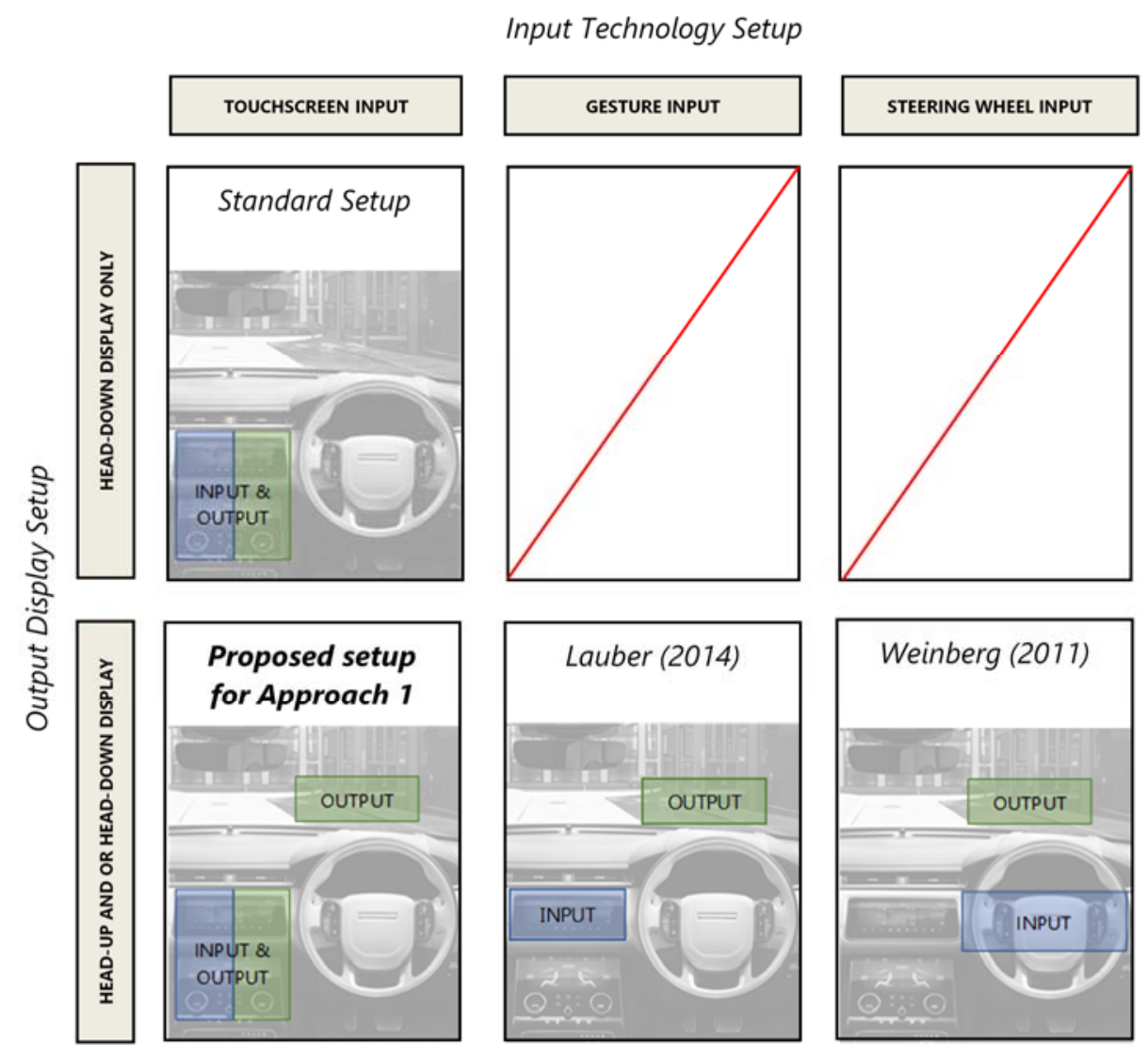

Figure 5 - Existing approaches that use a either a Head-up Display (HUD) or Head-down Display (HDD) to allow access to NDRA-based Information and the combination of input devices either tested previously or proposed for use in the present context

around the car meaning that NDRA information is consequently separated from DRA information. This approach can be seen in most production vehicles on the road today whereby DRA-related information is typically found directly in front of the driver (steering wheel, instrument cluster) and NDRA information is typically located in the centre console (climate, touchscreen). This separation may have been due to the emphasis in the driving literature on the negative impact of distraction on the DRA or simply because of the physical space available in the vehicle cabin. However, it is important to see if this subsequently leads to an impact on NDRA performance. Therefore, this conflict is explicated by the innovative approach developed here. This approach also promotes other SA-based design principles, such as, providing the operator an overview of all active goals (Endsley et al., 2003). 


\section{Contextual Cueing for the NDRA through a Head-Up Display (HUD)}

There are a number of risks associated with this approach, such as distraction (Lee et al., 2008) and information overload (Yeh et al., 2003). HUD use in other contexts is also known to be associated with cognitive tunnelling, where HUD information absorbs operator attention to the detriment of other important environmental information. In the aerospace domain, where HUDs are common, this has been shown to be avoidable through locating information away from the centre point of the pilot's view (Dowell et al., 2012; Jarmasz et al., 2005). Likewise, a HUD in the automobile would likely mitigate some potential for distraction by being situated in the periphery, out of line with the most commonly viewed portions of the surrounding environment. Happily, recent work supports the availability of peripheral vision information, and the subsequent availability of the peripheral driving environment when gazing to such information, in driving (Wolfe et al., 2019).

To successfully aid preparation, the display would also need to reinforce the driver's mental model of an NDRA such that they would be contextually cued as to how to interact (Chun, 2000). To achieve this functionality a Head-up Display (HUD) could allow for the information to be augmented over the road scene. Many examples of using a HUD to show DRA-based information exist (Charissis and Naef, 2007; Kim et al., 2013; Liu, 2003; Sojourner and Antin, 1990). However, only a few previous studies in the driving context look at using a HUD for NDRA based information (Lauber, Follmann, \& Butz, 2014; Weinberg, Harsham, \& Medenica, 2011). Each of these examples use a HUD to supplement different interaction technology such as steering wheel buttons (Weinberg et al., 2011) and gesture (Lauber et al., 2014). Neither found significant task performance improvements, this is possibly because both required relatively novel interactions that may have led to additional workload themselves (combinations already depicted in Figure 5). This was particularly evident in (Lauber et al., 2014) where the user was expected to hover their finger near a 
centrally mounted in-vehicle touchscreen, but at the same time look at a curser in the HUD. This suggests that separating the input and output elements may add extra demand that impacts task performance.

The input and output combinations given in these examples provide scope for an alternative combination where the Contextual Cue display is combined with a traditional touchscreen input (Figure 5, Lower Left). The display would act to keep the drivers NDRA Situation Model up to date such that when they did glance away from the road, they could be more efficient. This concept collocates NDRA information within the DRA field of view and will be known as the Collocation of NDRA Information Concept from now on. Gugerty, (1997) explained that one strategy for supporting driver awareness is by providing cues to support attention allocation, for example, spatially directing drivers to hazards that they may have missed. With greater access to NDRA information, the expectation would be that task performance with an NDRA will improve because of greater awareness. The proximity of the information to the driver's central field of view could, therefore, reduce the cost of having to glance far from the road scene (Hardiess et al., 2008; Wickens, 2002; Wickens and Liu, 1988).

\section{Interface Design - Collocation of NDRA Information Concept}

A simple yet appropriate conceptualisation to test this theory would be to directly mirror the information located in the centre console in the HUD. Taking direction from (Lauber et al., 2014; Weinberg et al., 2011), input would be through the touchscreen and so a glance away from the road would still be required to complete the task. However, the glance required should be shorter due to the information provided, allowing the driver to anticipate what to do next (Chiappe et al., 2015). Traditionally the centre console IVIS is oriented vertically (Figure 6). To be able to replicate this in a HUD the information would, therefore, need to be 


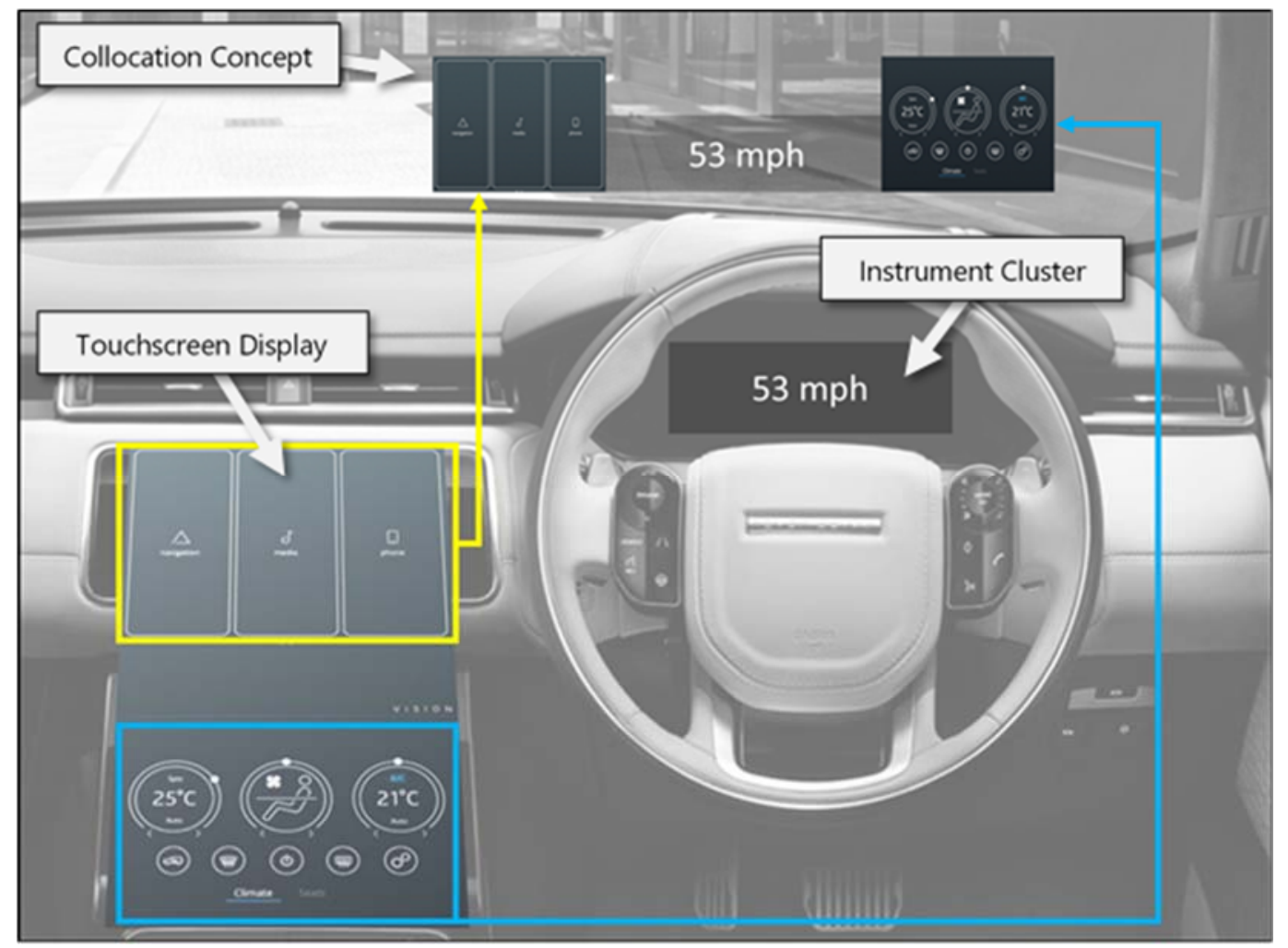

Figure 6 - Collocation concept, providing information about an NDRA in a head up location. The information in the HUD is separated into two regions. The left-hand side showing the top half of the centre screen, with the right-hand side showing the bottom half.

split to ensure compliance with the horizontal orientation of the HUD but also to prevent it obscuring the driving scene. This information would need to be positioned below the driver's field of view of the road ahead (approximately 6 degrees below their view of the road scene). This conceptualisation will form an IVIS to investigate Approach 1 experimentally and is discussed in the Evaluation section.

\section{Approach 2 - Conceptual Considerations}

To support the driver with DRA-based information when multitasking, the DRA would need to be broken down such that information could be designed to replace the visual channel when focus is away from the road. Two aspects that are fundamental to basic vehicle control are lane keeping and maintaining a safe distance to the vehicle in front. Performance with 
both has been known to reduce during periods of distraction (Lee et al., 2002; Peng et al., 2013). Therefore, by presenting this information using alternative parallel channels, the driver could potentially maintain awareness of the DRA even when focussed on an NDRA and, therefore, utilise the properties of Multiple Resources Theory (Wickens, 2008).

\section{Concurrent Information for the DRA}

Presenting concurrent information requires the use of one of the three key input modalities of the human; visual, auditory, and haptic. Meng and Spence, (2015); and Riener, (2011) both discuss the relative merits of each (Table 1). To develop multimodal IVIS, the design requirements that govern human performance such as Multiple Resources Theory (Wickens, 2008) and cross-modal communication effects (Spence, 2011) must be adhered to. Traditional vehicle systems warn the driver as they are about to leave the lane, or as they are about to

Table 1 - Relative merits of each human interaction modality as a feedback mechanism

\begin{tabular}{|c|c|c|}
\hline Modality & Advantages & Disadvantages \\
\hline $\begin{array}{l}\text { Visual } \\
\text { Highest Information } \\
\text { Capacity (30-45bits/s) }\end{array}$ & $\begin{array}{l}\text { - Fast \& high bandwidth } \\
\text { - Private } \\
\text { - Straightforward and common }\end{array}$ & $\begin{array}{l}\text { - Eyes have a limited field of } \\
\text { view } \\
\text { - Suffer from both } \\
\text { environmental and } \\
\text { physiological visibility issues } \\
\text { - Competition for the visual } \\
\text { resource when driving can } \\
\text { cause cognitive load issues. }\end{array}$ \\
\hline $\begin{array}{l}\text { Non-Speech Auditory } \\
\text { Mid Information } \\
\text { Capacity (40bits/s) }\end{array}$ & $\begin{array}{l}\text { - Eyes free } \\
\text { - Rapid Omni-directional detection } \\
\text { - Easy to convey spatial information }\end{array}$ & $\begin{array}{l}\text { - Interference from noise } \\
\text { - Can be difficult to localise }\end{array}$ \\
\hline $\begin{array}{l}\text { Haptic } \\
\text { Lowest Information } \\
\text { Capacity (2-56bits/s) }\end{array}$ & $\begin{array}{l}\text { - Many receptors on the body } \\
\text { - Relatively new and novel } \\
\text { - Less central to driving } \\
\text { - Doesn't increase visual or auditory } \\
\text { workload } \\
\text { - Disrupted least by NDRA } \\
\text { - Silent and Private }\end{array}$ & $\begin{array}{l}\text { - Requires learning } \\
\text { - Care needs to be taken on } \\
\text { making an intuitive mapping } \\
\text { design to avoid distracting } \\
\text { effects } \\
\text { - Only works if the user is } \\
\text { touching the surface }\end{array}$ \\
\hline
\end{tabular}


collide with a lead vehicle. However, the use of a multi-stage feedback that indicates absolute lane position and the distance to a car in front is less common. This concept supports awareness by utilising parallel processing and supporting both comprehension and prediction, two of the SA-based design principles (Endsley et al., 2003). To minimise complexity to the user and because the NDRA being used is visual-manual, the feedback was be provided in a single modality (visual, auditory or haptic) but each tested independently to understand whether any offer specific performance benefits.

\section{Interface Design - Multimodal DRA Information}

Two form of DRA information were considered, Lane keeping and Vehicle Headway. For Lane Keeping, a five-stage escalating feedback was designed (Biondi et al., 2014; Ho et al., 2014).
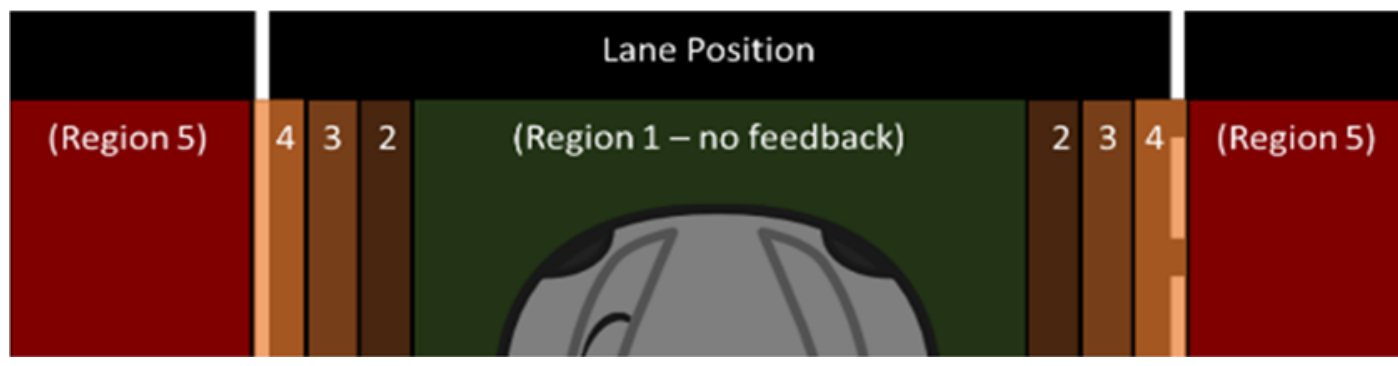

\begin{tabular}{|c|c|c|c|c|c|c|}
\hline & Description & $\begin{array}{l}\text { Upper } \\
\text { Limit } \\
\text { in feet fro }\end{array}$ & $\begin{array}{l}\text { Lower } \\
\text { Limit } \\
\text { ane centre }\end{array}$ & $\begin{array}{c}\text { Visual } \\
\text { Feedback }\end{array}$ & $\begin{array}{l}\text { Auditory } \\
\text { Feedback }\end{array}$ & $\begin{array}{c}\text { Haptic } \\
\text { Feedback }\end{array}$ \\
\hline Region 1 & No Feedback & +3 & -3 & -------- & --No Feedback-- & ------ \\
\hline Region 2 & $\begin{array}{l}\text { First level (lowest), } \\
\text { Triggered on the side of } \\
\text { drift }\end{array}$ & +3.5 & -3.5 & $\begin{array}{l}1 \text { bar } \\
\text { displayed on } \\
\text { side of drift }\end{array}$ & $400 \mathrm{~Hz}$ tone & $\begin{array}{c}100 \mathrm{~Hz} \\
\text { vibration @ } \\
20 \% \text { PWM }\end{array}$ \\
\hline Region 3 & $\begin{array}{l}\text { Second level (medium), } \\
\text { Triggered on the side of } \\
\text { drift }\end{array}$ & +4 & -4 & $\begin{array}{c}2 \text { bars } \\
\text { displayed on } \\
\text { side of drift }\end{array}$ & $600 \mathrm{~Hz}$ tone & $\begin{array}{c}100 \mathrm{~Hz} \\
\text { vibration @ } \\
\text { 30\% PWM }\end{array}$ \\
\hline Region 4 & $\begin{array}{l}\text { Third level (high), Triggered } \\
\text { on the side of drift }\end{array}$ & +4.5 & -4.5 & $\begin{array}{c}3 \text { bars } \\
\text { displayed on } \\
\text { side of drift }\end{array}$ & $800 \mathrm{~Hz}$ tone & $\begin{array}{c}100 \mathrm{~Hz} \\
\text { vibration @ } \\
40 \% \text { PWM }\end{array}$ \\
\hline Region 5 & $\begin{array}{l}\text { Highest level, Both sides } \\
\text { triggered simultaneously }\end{array}$ & +5 & -5 & $\begin{array}{c}3 \text { bars } \\
\text { displayed on } \\
\text { both sides, } \\
\text { blinking @ 2Hz }\end{array}$ & $\begin{array}{c}800 \mathrm{~Hz} \text { tone } \\
\text { pulsed at } 12 \mathrm{~Hz}\end{array}$ & $\begin{array}{c}100 \mathrm{~Hz} \\
\text { vibration @ } \\
50 \% \text { PWM }\end{array}$ \\
\hline
\end{tabular}

PWM = Pulse Width Modulation

Figure 7 - Lane keeping IVIS functionality 
The first stage (Figure 7, Region 1) was a safe region in the centre of the lane that produced no feedback. As the vehicle drifted left or right the feedback would inform the driver of the direction of drift such that feedback was presented on the side of the drift. The feedback escalated three times before reaching the final stage (Figure 7, Region 5), intended to replicate the activation point of current in-market lane departure systems. To prevent false activation, the system would need to know when an intentional lane crossing was taking place. This was done by suppressing lane feedback whenever the turn signal indicator was on.

For Vehicle Headway a similar form of continuous feedback was required (Figure 8). Again, the first stage produced no feedback (Figure 8, Region 1). This signified that a lead vehicle
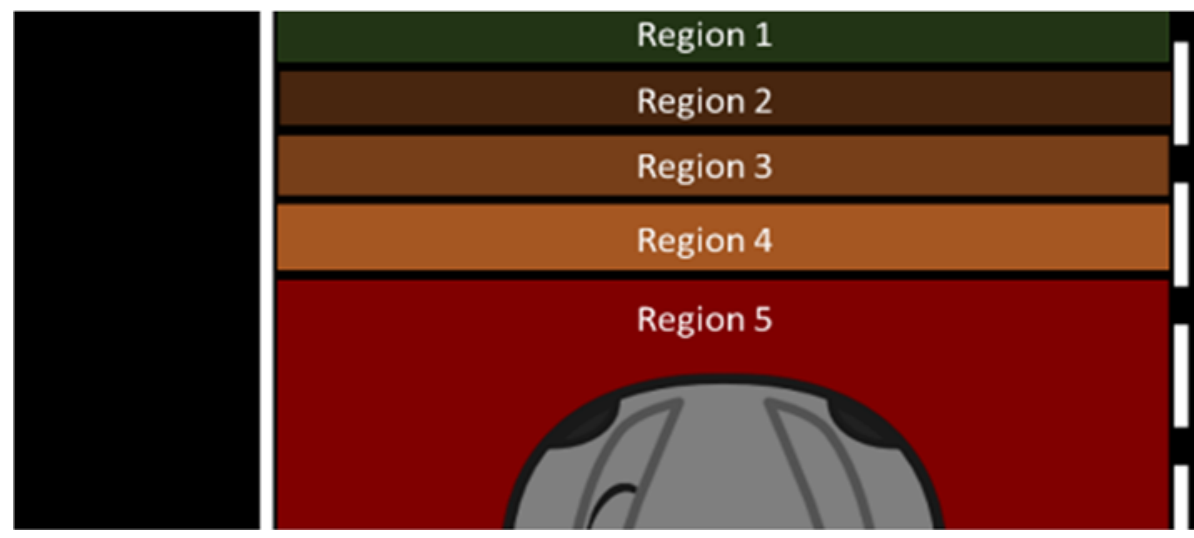

\section{Region 5}

\begin{tabular}{|c|c|c|c|c|c|}
\hline & Description & $\begin{array}{c}\text { Threshold } \\
\text { in feet from vehicle in front }\end{array}$ & $\begin{array}{c}\text { Visual } \\
\text { Feedback }\end{array}$ & $\begin{array}{l}\text { Auditory } \\
\text { Feedback }\end{array}$ & $\begin{array}{c}\text { Haptic } \\
\text { Feedback }\end{array}$ \\
\hline Region 1 & No Feedback & Greater than +400 & ----- & ---No Feedback--- & ---- \\
\hline Region 2 & First level (lowest) & $+400>+300$ & $\begin{array}{l}1 \text { graphical } \\
\text { bar in front }\end{array}$ & $\begin{array}{c}800 \mathrm{~Hz} \text { tone } \\
\text { pulsed at } 1.25 \mathrm{~Hz}\end{array}$ & $\begin{array}{c}100 \mathrm{~Hz} \\
\text { vibration @ } \\
\text { 15\% PWM }\end{array}$ \\
\hline Region 3 & Second level (medium) & $+300>+200$ & $\begin{array}{l}2 \text { graphical bars } \\
\text { in front }\end{array}$ & $\begin{array}{c}800 \mathrm{~Hz} \text { tone } \\
\text { pulsed @ } 2.5 \mathrm{~Hz}\end{array}$ & $\begin{array}{c}100 \mathrm{~Hz} \\
\text { vibration @ } \\
27 \% \text { PWM }\end{array}$ \\
\hline Region 4 & Third level (high) & $+200>+150$ & $\begin{array}{l}3 \text { graphical bars } \\
\text { in front }\end{array}$ & $\begin{array}{c}800 \mathrm{~Hz} \text { tone } \\
\text { pulsed @ } 5 \mathrm{~Hz}\end{array}$ & $\begin{array}{c}100 \mathrm{~Hz} \\
\text { vibration @ } \\
35 \% \text { PWM }\end{array}$ \\
\hline Region 5 & Intermittent feedback & Less than +150 & $\begin{array}{c}3 \text { graphical bars } \\
\text { in front, pulsed } \\
@ 2 \mathrm{~Hz}\end{array}$ & $\begin{array}{c}800 \mathrm{~Hz} \text { tone } \\
\text { pulsed @ } 7.5 \mathrm{~Hz}\end{array}$ & $\begin{array}{c}100 \mathrm{~Hz} \\
\text { vibration@ } \\
40 \% \text { PWM }\end{array}$ \\
\hline
\end{tabular}

PWM = Pulse Width Modulation

Figure 8 - Vehicle headway IVIS functionality 
was either not present or too far ahead of the host to be considered a threat. As soon as a vehicle was within a predetermined range, the feedback would begin. It then scaled three times until reaching the final level (Figure 8, Region 5). As with lane position, the final region was intended to replicate the point at which modern day forward collision warning systems would activate. Unlike the lane feedback, turn signal indication did not suppress the feedback but was only be active for vehicles located in the same lane as the host.

\section{Design Concepts for Lane Keeping and Vehicle Headway}

Three independent interface concepts were proposed to investigate communication through each of the primary human senses: Visual, Auditory and Haptic. All three are depicted in

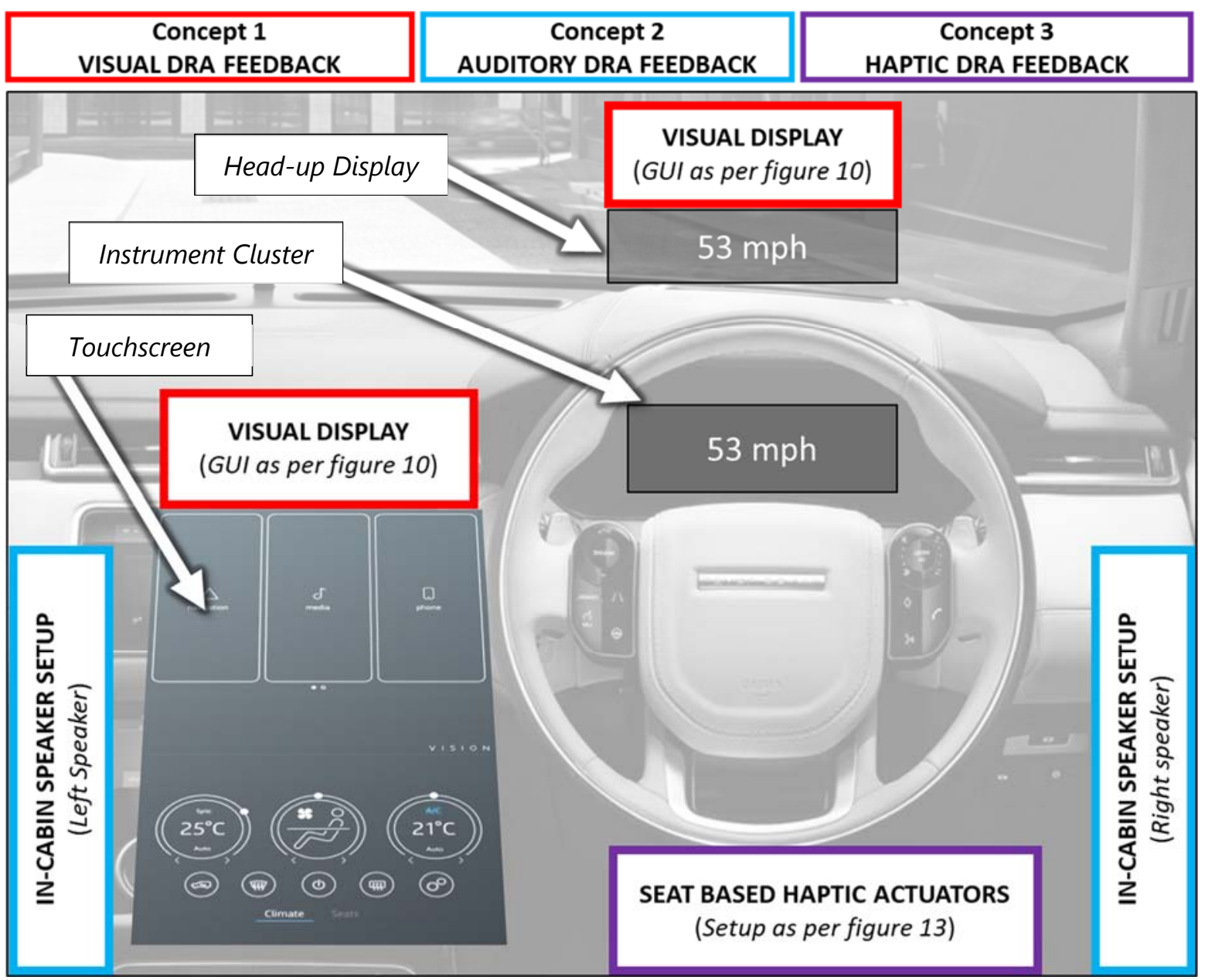

Figure 9 - IVIS providing lane and vehicle headway feedback. The three conditions are shown in the red (visual), blue (auditory) and purple (haptic) boxes 
Figure 9 and explained in the following sections. While Figure 9 shows the IVIS on the same diagram, they were not active concurrently but were evaluated as three independent concepts.

Visual Multimodal Concept (Figure 9, red boxes) - A real-time GUI was developed to represent each function described in the previous section. The information was displayed in the HUD, as an augmented overlay, but also on a secondary screen located next to an NDRA display in the centre console. This allowed the driver to still maintain awareness of the DRA without needing to look back at the road. As discussed, the feedback escalated for both Lane

Vehicle Headway Feedback - The three bars correspond to vehicle headway. When no vehicle is present, all bars are invisible. When a car is present and as the headway reduces, the bars become visible (farthest, upper bar, first and closest, lower bar, last) corresponding to regions 2, 3 and 4 described in Figure 8. Once the final region is entered, the three bars start to blink.

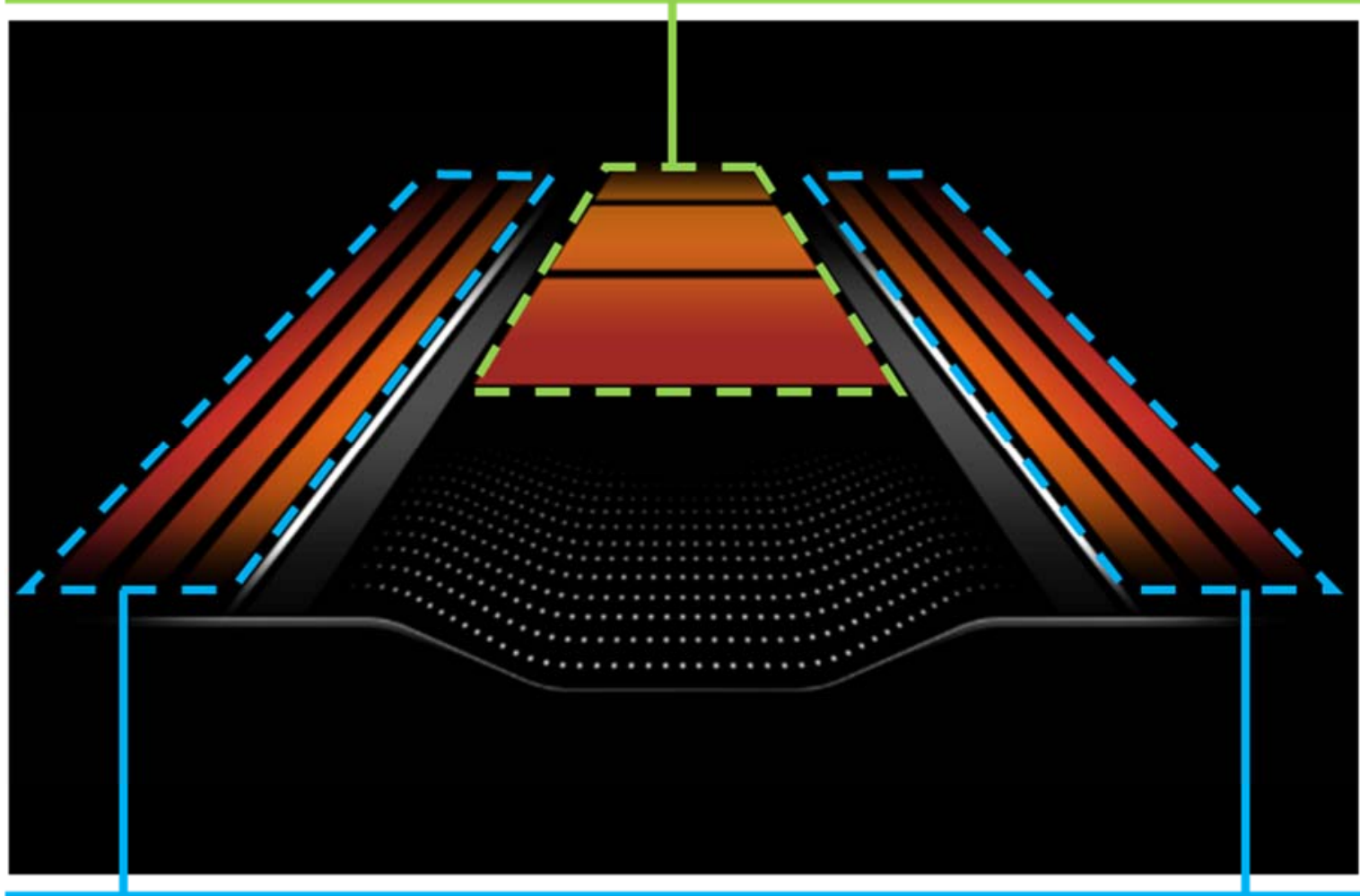

Lane Departure Feedback - The three bars either side of the vehicle correspond to the location of the vehicle within the lane. When the vehicle is safely in the centre of the lane none are visible. As the car drifts left, corresponding to regions $X, Y$ and $Z$ defined in Figure $X$, the bars appear until the final region is reached, indicating a lane departure, at which point the bars on the left will blink. The functionality on the right-hand side is a mirror image of the functionality on the left.

Figure 10 - Visual DRA feedback concept Graphical User Interface (GUI) design and functionality 
Keeping and Vehicle Headway, as shown by the parallel horizontal and vertical bars in Figure 9. Once stage five was reached (Figure 7 and Figure 8), the bars flashed intermittently (2 Hertz). The visual feedback was designed to align with good human factors principles for visual display design (Bennett et al., 2012; Bhise, 2016; Horowitz and Dingus, 1992; Seppelt and Lee, 2007; Vicente, 2002).

Auditory Multimodal Concept (Figure 9, blue boxes) - The auditory concept was designed to operate as the auditory analogue of the visual feedback (Figure 10). A tonal strategy was used for Lane Keeping (400, 600, 800 Hertz) whilst beeps were used for Vehicle Headway (800 Hertz@1.25, 2.5, 5 and 7.5 Hertz). For both feedbacks, no audio was presented during the lowest level of severity but increased in intensity as severity increased (Figure 7 and Figure 8). At the highest severity level, the feedback would beep to indicate a critical situation. Directional sound was used for Lane Keeping, while for Vehicle Headway the feedback was played through both speakers simultaneously as the threat was directly in front (Bellotti et al., 2002). The feedback was calibrated to be heard above background sound and the levels adjusted to ensure a balance between perceived urgency and annoyance (Gonzalez et al., 2012; Nees and Walker, 2011).

Haptic Multimodal Concept (Figure 9, purple boxes) - As with the auditory concept, the haptic feedback was designed to operate as the haptic analogue of the visual feedback. The haptic devices were designed, built and integrated into the seat to spatially differentiate between the Lane Keeping and Vehicle Headway following a similar approach to (Dass et al., 2013; Ji et al., 2011). The seat back was used for Lane Keeping (one on each side) and the seat base was used for vehicle headway (one underneath each thigh). Unlike the auditory feedback, separate channels were available for the two IVIS and hence the actual feedback was consistent between Lane Keeping and Vehicle Headway. At level one, no feedback was 


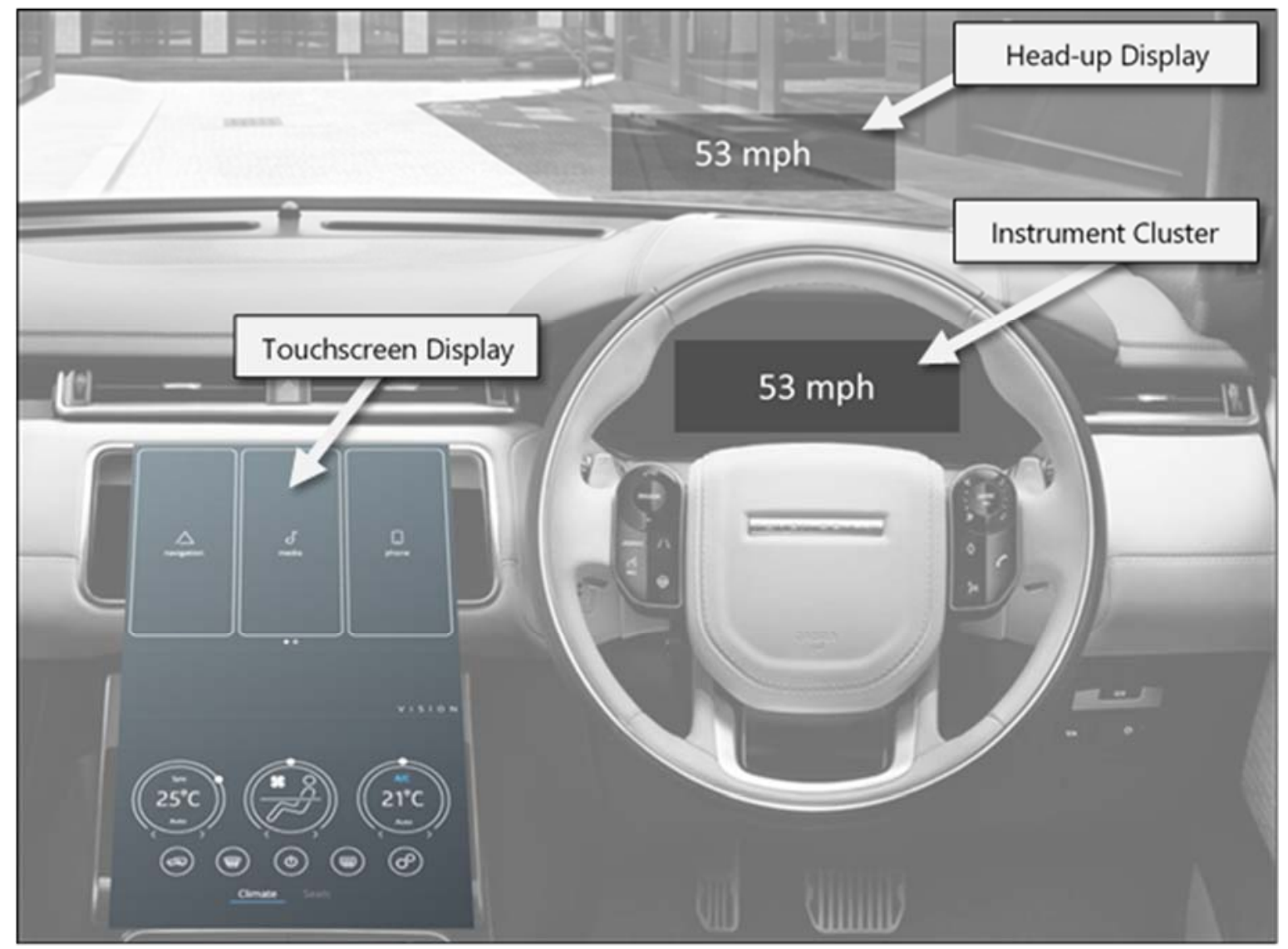

Figure 11 - Baseline interface condition, no additional support interfaces

present, for levels two, three and four, a continuous vibration was used that escalated as the warning became more severe. When in level five the feedback pulsed at 2 Hertz. Good practice was followed to calibrate the intensity and frequency (Ji et al., 2011).

Baseline Concept (Figure 11) - Before evaluation could begin, a baseline condition was required. This was conceptually like the previous examples but did not contain the additional SA-based support, consisting of the same basic components (HUD, instrument cluster and touchscreen). This would allow for an assessment to be made of how well the additional content was supporting the driver.

\section{Face Validation}

To ensure that the concepts developed stayed true to SA design principles and appropriate for 
use, a face validation exercise was carried out (Borenstein, 1998). Each concept was assessed with both the planned DRA and NDRA by two independent domain experts and evaluated twice (paper-based and functional prototype). A critical assessment was carried out and feedback provided to refine the systems further until they were satisfied as being representative of a modern motor vehicle IVIS. For example, Expert 1 requested that the text size on the HUD needed to be bolder, while Expert 2 requested that the difference between the haptic feedback levels were increased for saliency. This included a final evaluation of the concepts mocked up in a driving simulator setup.

\section{Evaluating the impact on task performance of IVIS design to support driver SA during in-vehicle multitasking}

The concepts developed in sections 2 and 3 follow the underlying approach of Unconstrained Design to improve driver SA and hence provide optimised conditions for in-vehicle multitasking. To understand whether the concepts could achieve the objective of improving task performance during in-vehicle multitasking, an experimental investigation was carried out in a driving simulator. The two types of support IVIS evaluated were targeted at supporting the different activities. The NDRA support IVIS (collocation condition) was designed to support NDRA task performance prior to and during multitasking, while the DRA support IVIS (visual, auditory and haptic) were designed to support the DRA during multitasking. The main hypothesis predicted that:

Hypothesis 1 (H1) - The Collocation of NDRA Information would improve NDRA task performance when compared with the baseline condition.

Hypothesis 2 (H2) - The Multimodal DRA Information (visual, auditory, haptic) would improve DRA task performance when compared with the baseline condition. 
A 1 x 5 within-subjects, repeated measures design was used allowing for comparisons between each condition. Only one independent variable was present, Interface Type, containing five levels corresponding to the IVIS designs presented earlier:

\section{Traditional IVIS Setup}

Condition 1) Baseline, no SA-based support IVIS (Figure 10)

\section{Approach 1 - Collocation of NDRA Information}

Condition 2) Collocation concept (Figure 6)

\section{Approach 2 - Multimodal DRA information}

Condition 3) Multimodal Visual concept (Figure 9)

Condition 4) Multimodal Auditory concept (Figure 9)

Condition 5) Multimodal Haptic concept (Figure 9)

Four Dependent Variables (DVs) were selected to highlight whether the IVIS were having the predicted effect (Table 2). The measures followed an embedded approach, with SA being linked to a response associated with the task. The first DV was the Percentage of Time spent in Lane Centre (PTLC) because the IVIS was designed to keep the driver in the centre of the lane. A traditional measure, such as Standard Deviation of Lane Position (SDLP), was not well suited because of the likelihood that the feedback would increase steering activity. The second DV was the Percent Time spent Following a Vehicle (PTFV). Typically, Time To Collision (TTC) is used for scenarios when a driver is following a lead vehicle (Jamson and Merat, 2005; Lee et al., 2002). However, because drivers in this study were expected to overtake, the measure needed to include times when no lead vehicle was present.

The third measure was Mean Glance Time to Button Press. To characterise performance with the NDRA, a response measure was selected that would indicate whether the additional information was increasing awareness to progress the task. The information provided in the 


\begin{tabular}{|c|c|c|c|}
\hline & & H1 & $\mathrm{H} 2$ \\
\hline Measure & Activity & $\begin{array}{c}\text { The NDRA support IVIS would improve } \\
\text { NDRA task performance when compared } \\
\text { with the baseline condition }\end{array}$ & $\begin{array}{c}\text { The DRA support IVIS would improve } \\
\text { DRA task performance when compared } \\
\text { with the baseline condition. }\end{array}$ \\
\hline $\begin{array}{l}\text { Percent Time } \\
\text { in Lane } \\
\text { Centre }\end{array}$ & DRA & $\begin{array}{l}\text { We expected the percent time in lane } \\
\text { centre to be unchanged with respect to } \\
\text { the baseline. }\end{array}$ & $\begin{array}{l}\text { We expected the percent time in lane } \\
\text { centre to be greater with respect to the } \\
\text { baseline. }\end{array}$ \\
\hline $\begin{array}{l}\text { Percent Time } \\
\text { Following a } \\
\text { Vehicle }\end{array}$ & DRA & $\begin{array}{l}\text { We expected the percent time } \\
\text { following a vehicle to be unchanged } \\
\text { with respect to the baseline. }\end{array}$ & $\begin{array}{l}\text { We expected the percent time } \\
\text { following a vehicle to be greater with } \\
\text { respect to the baseline. }\end{array}$ \\
\hline $\begin{array}{l}\text { Mean Glance } \\
\text { Time to } \\
\text { Button Press }\end{array}$ & NDRA & $\begin{array}{l}\text { We expected the mean glance time to } \\
\text { button press to be reduced with } \\
\text { respect to the baseline. }\end{array}$ & $\begin{array}{l}\text { We expected the mean glance time to } \\
\text { button press to be unchanged with } \\
\text { respect to the baseline. }\end{array}$ \\
\hline $\begin{array}{c}\text { Attention } \\
\text { Management }\end{array}$ & Both & $\begin{array}{l}\text { We expected the mean AttenD value to } \\
\text { be increased with respect to the } \\
\text { baseline. }\end{array}$ & $\begin{array}{l}\text { We expected the mean AttenD value to } \\
\text { be increased with respect to the } \\
\text { baseline. }\end{array}$ \\
\hline
\end{tabular}

Collocation Concept aimed to cue the driver such that when they looked away from the road they could operate more efficiently. This was measured as the mean amount of time the driver spent glancing away from the road between each button press, not including the time spent looking at the road. The fourth and final DV was the AttenD algorithm (Kircher and Ahlstrom, 2009). AttenD provides insight into how a driver balances their visual attention between activities. The algorithm produces a value that increments or decrements based upon where the driver is looking (Figure 12). Broadly speaking, the value increases when the driver is looking at the road (Figure 12, blue regions labelled A) and decreases when not (Figure 12, orange regions labelled C). When looking at the instrument cluster or mirrors, a short delay period precedes the decrease to recognise the importance of this to DRA-based SA (Figure 12, yellow regions labelled D).

One complexity of this setup is the addition of a HUD showing different task-related 


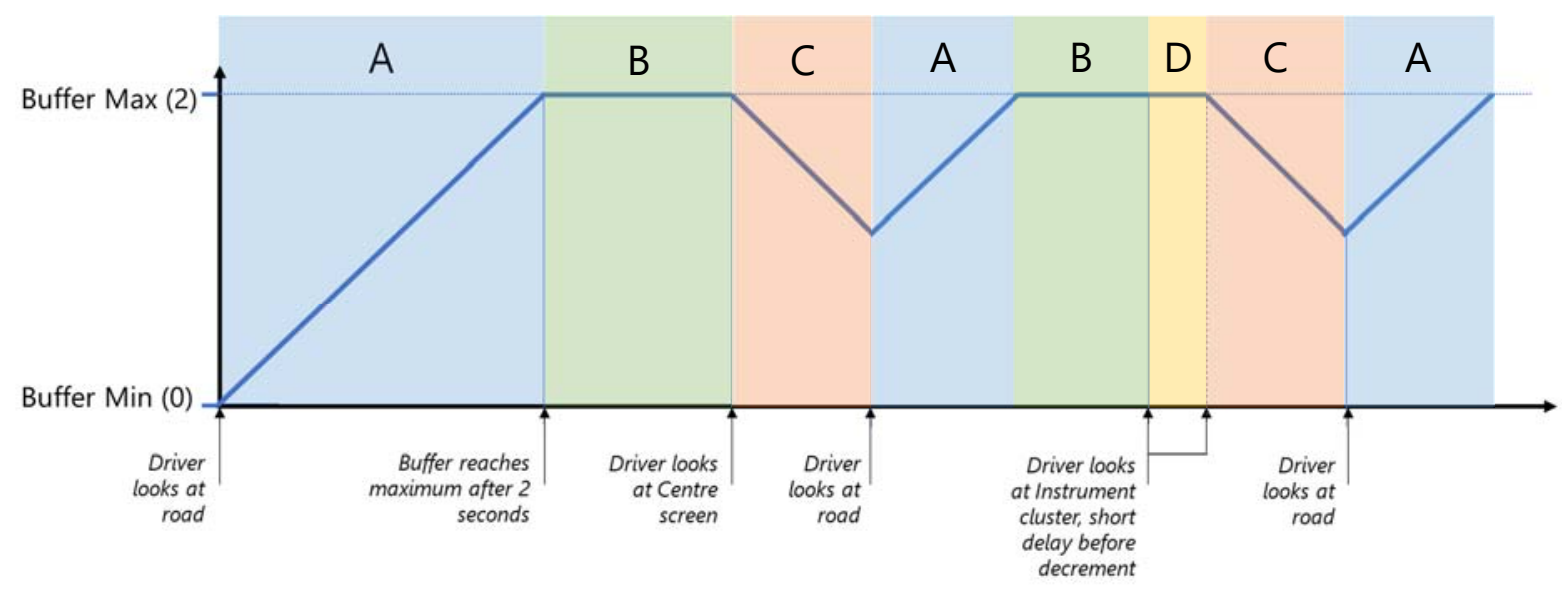

Figure 12 - A example output trace of the AttenD algorithm

information. In theory, because of the geometric location of the HUD and its proximity to the road scene, this could be interpreted differently based upon what the user is looking at. As current eye tracking cannot determine what the driver is looking at depth-wise, the region will be coded neutrally and therefore whenever the driver is looking at the HUD, the buffer value will remain the same. As soon as they glance to another region, the ruleset defined in (Kircher and Ahlstrom, 2009) will be followed. For consistency, this will be the case during all experimental conditions.

\section{Experimental Setup}

A low fidelity driving simulator setup was used that consisted of a right-hand drive vehicle with an adjustable seat and steering wheel. A Land Rover Discovery ${ }^{\mathrm{TM}}$ steering wheel was attached to a G27 gaming wheel (Logitech, Switzerland) and connected to a PC which hosted the driving simulator software. An 85" Liquid Crystal Display (LCD) was used to display the forward road scene. The setup contained a 12.3" LCD Cluster display, a HUD, side mirror displays, and a centre console-mounted touchscreen with two display areas (upper and lower). The lower display was in reach of the driver and was used for all touchscreen operations, while the upper display was used for any additional visual support (i.e. visual multimodal concept). 


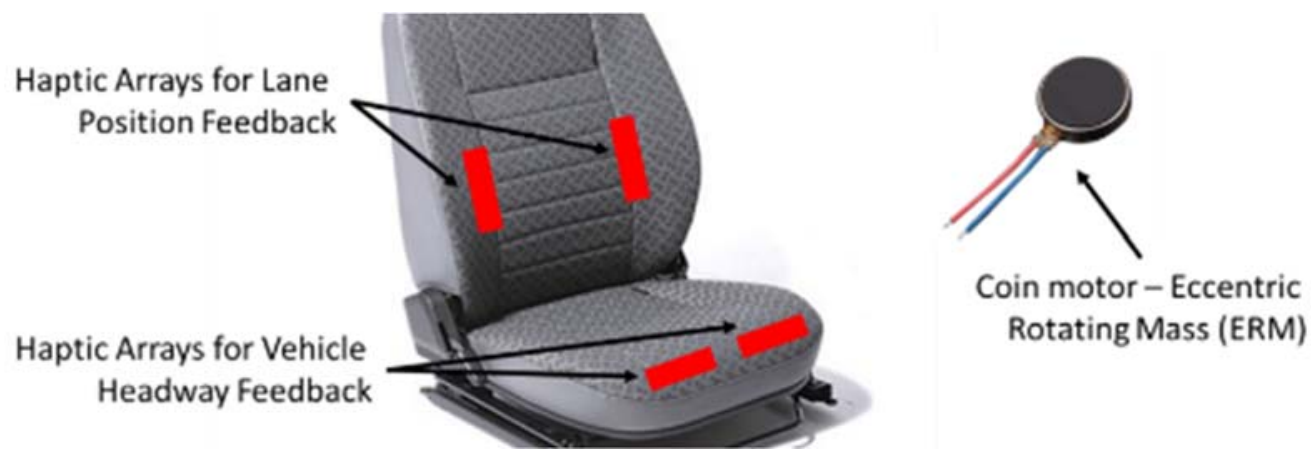

Figure 13 - Haptic array configuration for the lane position and vehicle headway feedback

All interface components were connected to a desktop PC that also acted as the data collection platform. To achieve the Auditory multimodal concept, speakers (Logitech, Switzerland) were located either side of the driver, used for both the auditory feedback and the sound of the driving simulator. The volume levels were set such that the feedback could be clearly heard above the driving scenario audio. For the Haptic multimodal concept, four haptic strips were fitted to the seat in the configuration shown in Figure 13. Each strip contained 5 Eccentric Rotating Mass (ERM) coin motors (Precision Microdrives, London), driven by an Arduino board and connected to an independent power supply. The haptic strips were calibrated with each driver prior to use. The HUD was created using a glass reflective

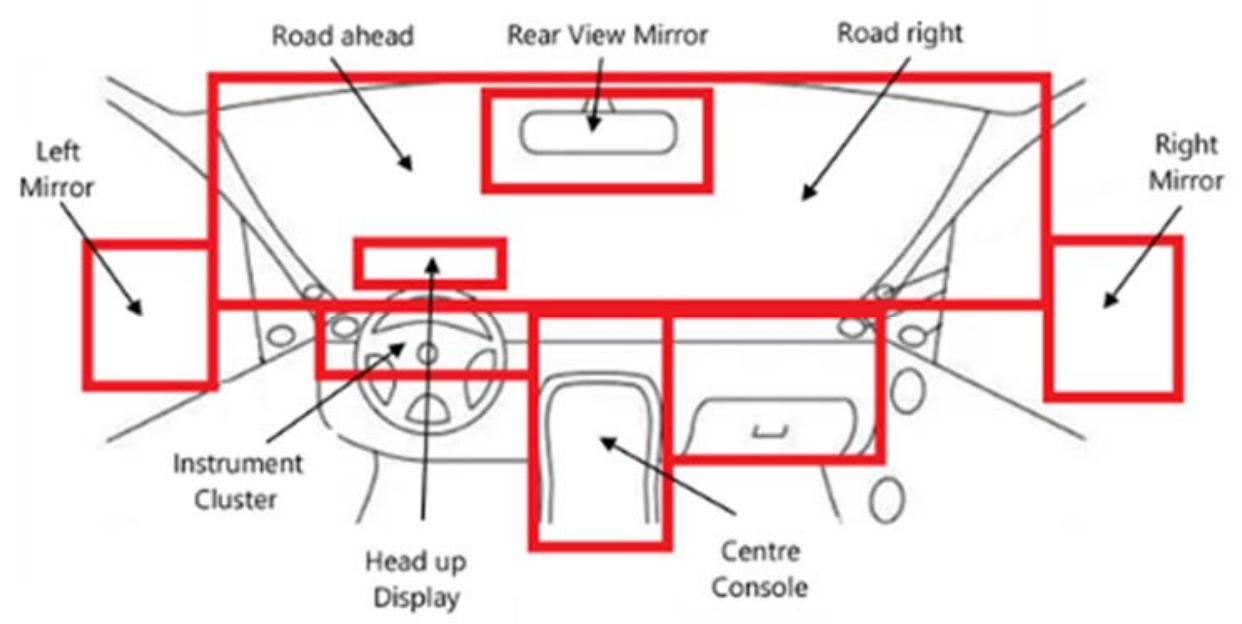

Figure 14 - In-vehicle regions used to code eye-glance data during the experimental runs 
teleprompter that created a virtual image between the driver and the road scene. The HUD contained an image size of 10 degrees horizontally and 4 degrees vertically, had a look down angle of approximately 6 degrees to the top of the image and was centralised to the driver. The virtual image appeared at approximately two meters.

A two-camera eye tracker (SmartEye, Sweden) logged eye glance locations. One camera was located directly in front of the driver, but low enough not to obscure the HUD image and one close to the centre console touchscreen display to maximise accuracy. The regions used can be seen in Figure 14 and were tracked at a refresh rate of approximately $30 \mathrm{~ms}$. For the driving environment, STISIM Drive version 3 (Hawthorne, California) was used. All driving data was streamed to the data collection PC using a serial port. The PC also captured data

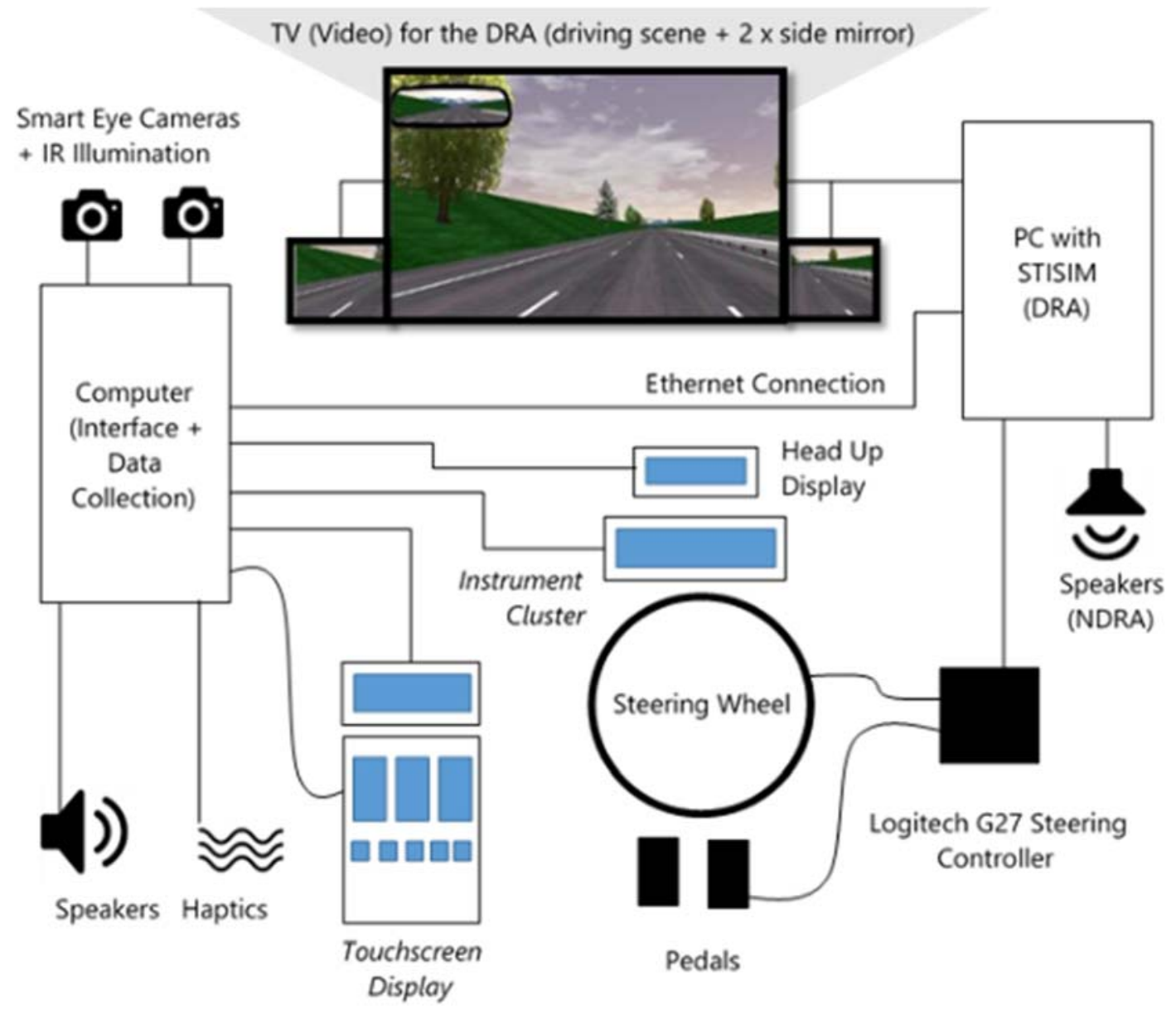

Figure 15 - Experimental setup 
associated with the NDRA as well as the eye glance locations. All data was synchronised using a UNIX timestamp and stored in a CSV file for post-processing. The entire setup can be seen in Figure 15.

\section{Participants}

Independent members of the general public were recruited and pre-screened for effects of simulator sickness (Golding, 1998) leaving thirty participants. The mean age was about forty years (+/- ten years) and a sixty / forty split of males to females. To aid the accuracy of the eye tracker, only participants who didn't require glasses to drive were recruited. All held full UK drivers licences with at least five years' experience and an annual mileage of greater than 5000 miles

\section{Task Design - The Driving Related Activity}

The driving scenario used was a three-lane UK highway designed to last approximately 30 minutes travelling at $80 \mathrm{mph}$. The layout and traffic conditions were consistent, but the vehicle types changed between runs to reduce familiarity with the scenario. Each run lasted approximately 10-15 minutes. The aim of the task was to maintain $70 \mathrm{mph}$ and stay in the left-hand lane of the highway. If a slower moving vehicle appeared in the same lane, to challenge this behaviour, the driver was expected to overtake the vehicle as safely and as efficiently as possible. This happened between 8 and 10 times during the 10-15-minute drive time. Once an overtake manoeuvre was complete, they were expected to move back into the left-hand lane as soon as possible. A series of NDRAs were attempted (five tasks in total) during each run and once all five were complete the driver was asked to pull onto the hard shoulder and stop, signalling the end of the DRA. 
Task 1 - Navigating to and finding a music track in a structured list

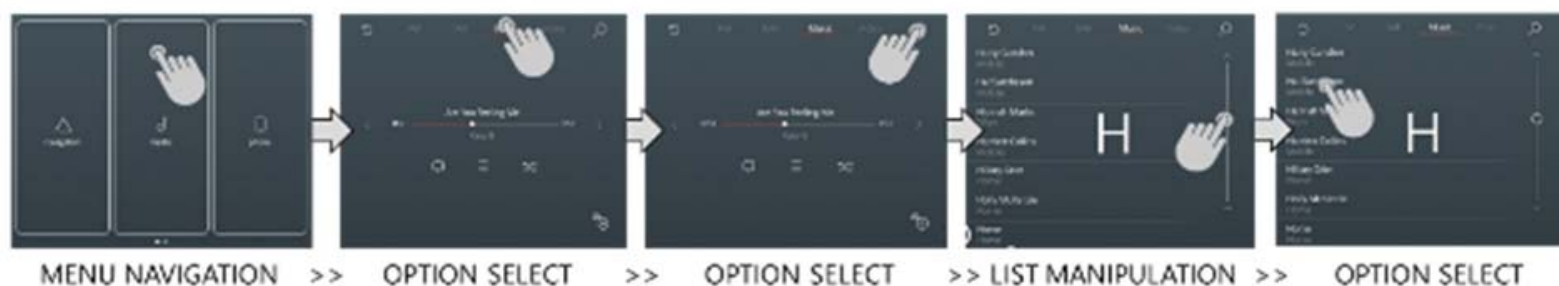

Task 2 - A long typing task, destination entry. The driver was required to enter a number and street name using an onscreen QWERTY keyboard, each destination requiring approximately $15-20$ button presses
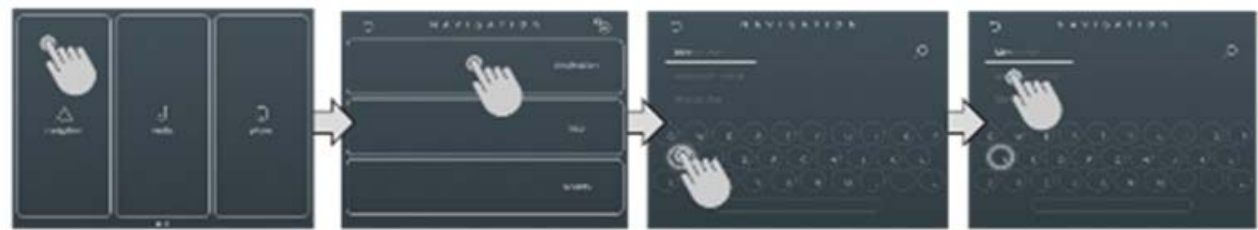

MENU NAVIGATION $>$ OPTION SELECT $\quad>$ QWERTYINPUT $>$ OPTION SELECT

Task 3 - A short typing task, phone contoct. This required opproximotefy 8-12 button presses using on onscreen QWERTY keyboard
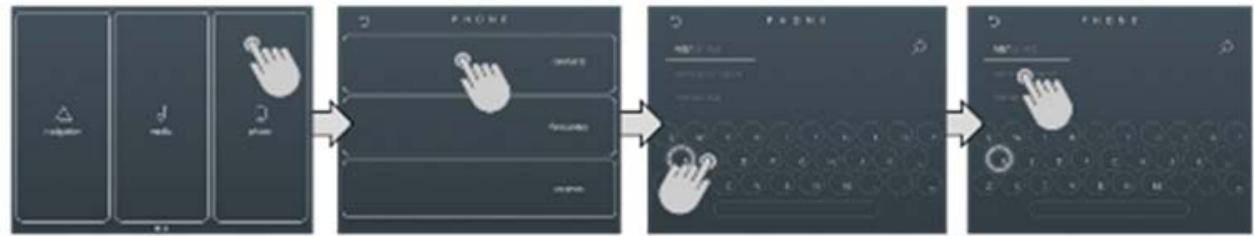

MENU NAVIGATION $>$ OPTION SELECT $>$ QWERTYINPUT $>$ OPTION SELECT

Task 4 - A settings task, where the driver had to locate a setting and turn it off. The setting was different each time but could be found on the some poge of the interfoce

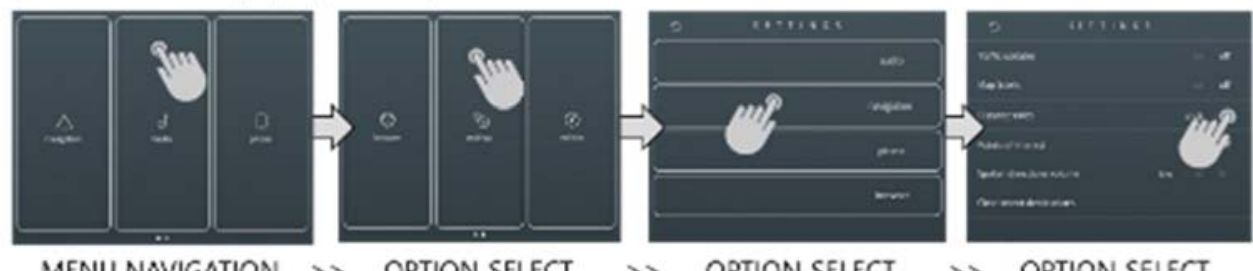

Task 5 - To adjust the climote control setting from one temperature setting to another, the torget temperature was different each time

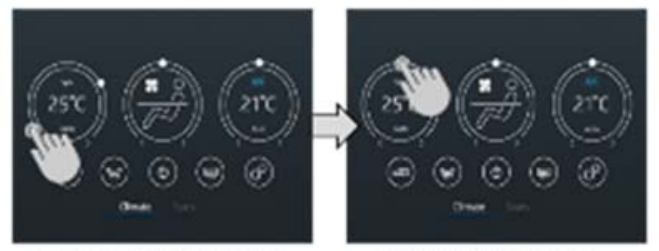

ADJUSTMENT START $>>$ ADJUSTMENT END

Figure 16 - Interaction flow for the five NDRA activities, circles indicate touch points 


\section{Task Design - The Non-Driving Related Activity}

Five visual-manual NDRA's were designed for the centre console touchscreen (Figure 16). These tasks were typical of the tasks used in similar experiments focussed on testing NDRA activity in-vehicle and were representative of typical NDRAs from a contemporary vehicle. The tasks were programmed using Qt v 6.0 (Espoo, Finland). All drivers were asked to complete all five tasks. The tasks were counterbalanced to avoid any effects of ordering on the results. These tasks were evaluated as part of the face validation exercise described earlier.

\section{Procedure}

The project was approved by the Cambridge University Engineering Department ethical panel prior to starting the study. Participants attended a time slot lasting approximately two hours and upon arrival were welcomed and provided refreshment. After reading a trial information sheet and signing a consent form when ready to begin. Participants were informed that they could withdraw at any point during the study if they felt uncomfortable in anyway. They then sat in the simulator, adjusted the setup to feel comfortable and were explained the details of the setup. During this time the eye-tracker was calibrated. The trial took in total between 90 and 120 minutes to run. The full procedure can be seen in Table 3.

\section{Results}

Thirty participant's data was successfully collected and post-processed using Microsoft Excel $^{\mathrm{TM}}$ (Seattle, United States of America) before being analysed using Minitab ${ }^{\mathrm{TM}}$ statistical software (Pennsylvania, United States of America). Any statistical outliers were removed and 
Table 3 - Experimental procedure

\begin{tabular}{|c|c|c|}
\hline & Stage & Description \\
\hline 1 & $\begin{array}{c}\begin{array}{c}\text { Pre-trial } \\
\text { questionnaire }\end{array} \\
(10 \text { mins })\end{array}$ & $\begin{array}{l}\text { To collect basic participant information, such as age, driving experience } \\
\text { and device familiarity. }\end{array}$ \\
\hline 2 & $\begin{array}{l}\text { Training Period } \\
\text { (30-45 mins })\end{array}$ & $\begin{array}{l}\text { Participants were trained to criteria on each IVIS to enhance their } \\
\text { awareness of each activity. For the DRA, the training involved the } \\
\text { demonstration of each IVIS concept (baseline, collocation, visual, } \\
\text { auditory and haptic). The NDRA training followed a train to criteria } \\
\text { approach. The facilitator walked the participant through each step of } \\
\text { each task before asking them to carry out each task individually. Once } \\
\text { the participant had completed the task five times in a row they could } \\
\text { move onto the next. Any failures and the success counter was reset. } \\
\text { (Hayes et al., 1953; Langdon et al., 2010; Rogé et al., 2014) }\end{array}$ \\
\hline 3 & $\begin{array}{c}\begin{array}{c}\text { Familiarisation } \\
\text { Run }\end{array} \\
\text { (20-40 mins })\end{array}$ & $\begin{array}{l}\text { Each participant drove to become familiar with the driving simulator } \\
\text { and the IVIS. The more familiar the participant with the IVIS, the more } \\
\text { able the will be at comprehending its meaning during multitasking. } \\
\text { Each IVIS was activated in turn and the participant asked to familiarise } \\
\text { themselves for around five minutes each. They were also encouraged } \\
\text { to use the NDRA interface whilst doing so. The experimenter was then } \\
\text { able to judge how well they could drive in the simulator and how able } \\
\text { they were with the IVIS. When ready they were asked to stop so that } \\
\text { the trial could commence. }\end{array}$ \\
\hline
\end{tabular}

Condition 1, 2, 3,

4 4 and 5

(15 mins each)

The conditions and tasks were counterbalanced for each participant to minimise any effects of ordering. The simulator was restarted after each run.

Post-Trial

5 Questionnaire

To collect some subjective feedback and preference data from the participants. Each was thanked for participation and were rewarded (10 mins) financially for their time.

Mean (M) and Standard Deviation (SD) was calculated for each of the dependent variables. All data was normally distributed and passed tests for equal variances meaning that one-tailed repeated measures ANOVA could be used. Any post hoc tests were carried out using Tukey 
HSD pairwise comparisons to establish any main or interaction effects $(p<.05)$. The focus was on multitasking, and so only data associated with the multitasking periods is reported.

For Attention Management (AM, Figure 17), the AttenD algorithm was used, with HUD coded neutrally (Kircher and Ahlstrom, 2009). The mean value produced a significant main effect of Interface Type $[F(4,146)=5.54, p=.000]$. The Collocation condition $(M=$ 1.2327) produced a higher mean than the Baseline $(M=1.0661, p=0.002)$, Multimodal Visual $(M=1.0944, p=0.016)$ and Multimodal Haptic $(M=1.0965, p=0.009)$, but not Multimodal Auditory $(M=1.1830$, n.s $)$.

For Percent Time spent in Lane Centre (PTLC, Figure 18), a significant main effect of Interface Type $[F(4,111)=3.89, p=.005]$ was found. The Multimodal Auditory condition $(M=87.6 \%)$ produced a higher PTLC value than the Baseline $(M=82 \%, p=.003)$ and Multimodal Visual $(M=82.7 \%, p=.032)$, but not the Multimodal Haptic $(M=84.1 \%, n . s)$ or Collocation concept $(M=84.7 \%, n . s)$.

For Percent Time spent Following a Vehicle (PTFV, Figure 19) a significant main effect of Interface Type $[F(4,113)=2.92, p=.024]$ was found. The Multimodal Haptic condition $(M=18.59)$ was found to have a significantly higher PTFV than Collocation concept $(M=$ 9.45, $p=.014)$ but not the Baseline $(M=12.85, n . s)$, Multimodal Visual $(M=14.21, n . s)$ or Multimodal Auditory ( $M=16.59$, n.s $)$.

For Mean Glance Time to Button Press (MGTBP, Figure 20) a significant main effect of Interface Type $[F(4,111)=4.86, p=.001]$ was found. The Collocation concept $(M=$ 0.987) produced a lower MGTBP than the Baseline $(\mathrm{M}=1.106, p=.014)$, Multimodal Auditory $(M=1.097, p=.001)$, Multimodal Visual $(M=1.112, p=.018)$ and Multimodal Haptic $(M=1.136, p=.010)$. 


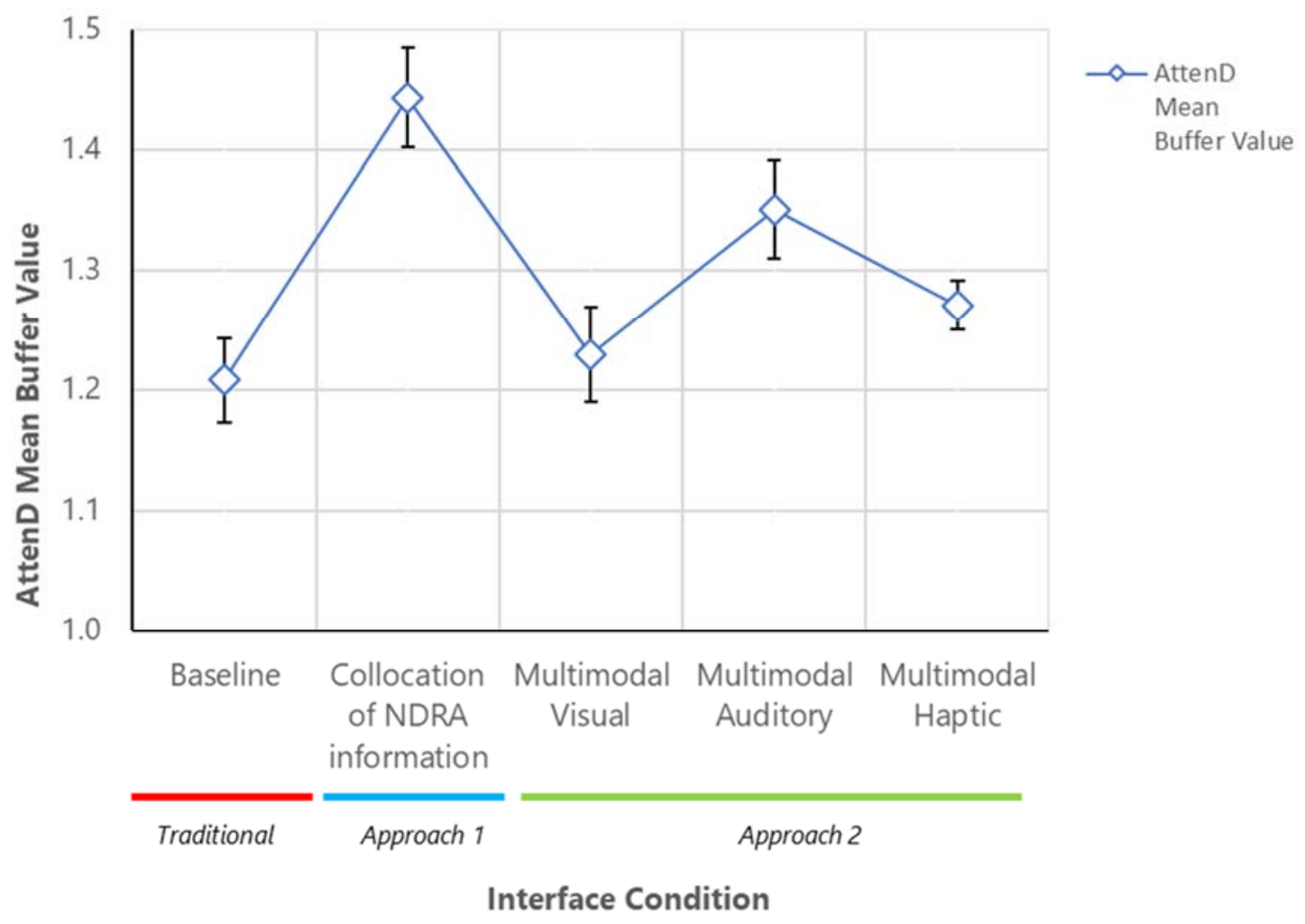

Figure 17 - AttenD mean value during multitasking by interface condition

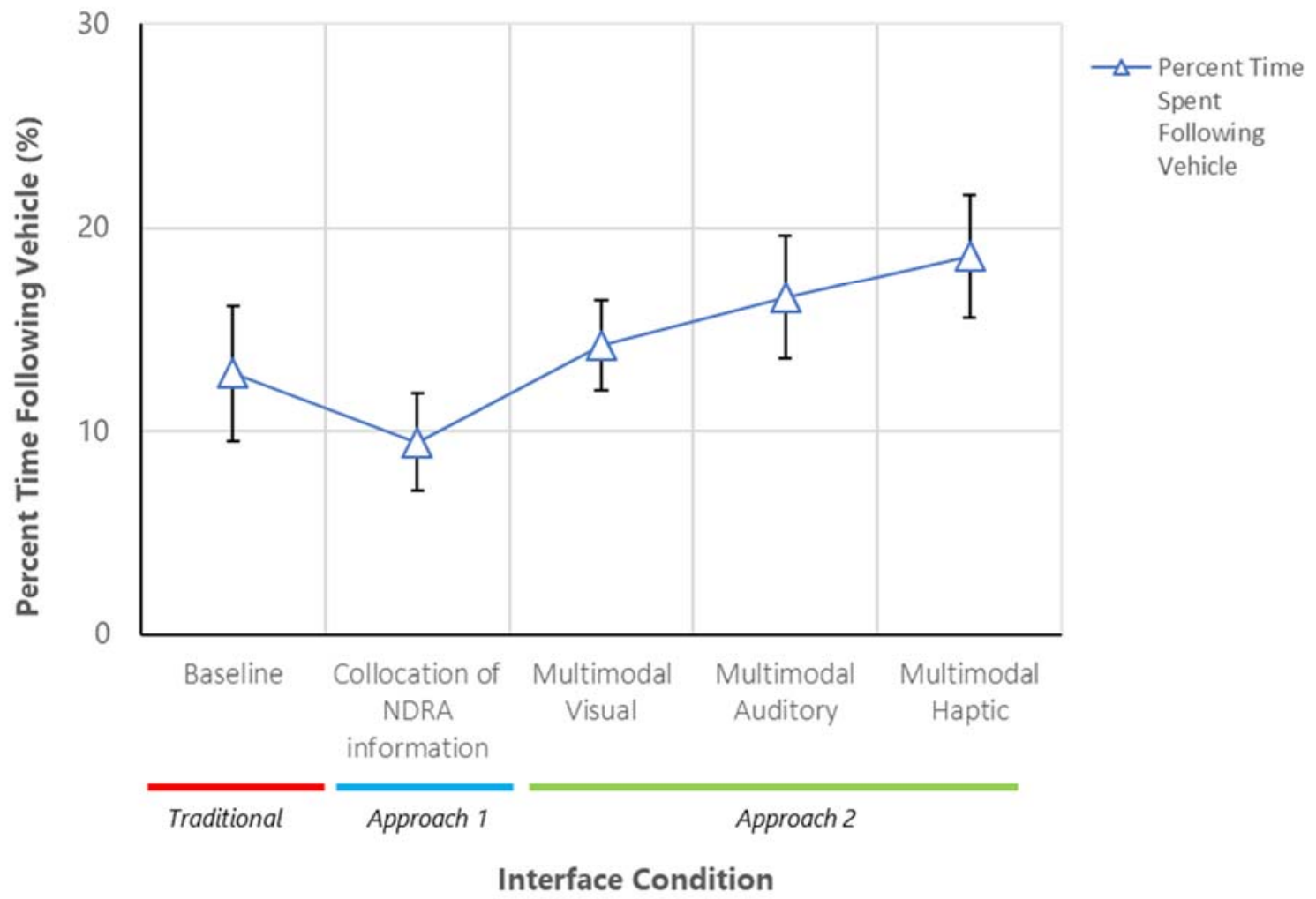

Figure 18 - Mean percent time spent in lane centre during multitasking by interface condition 


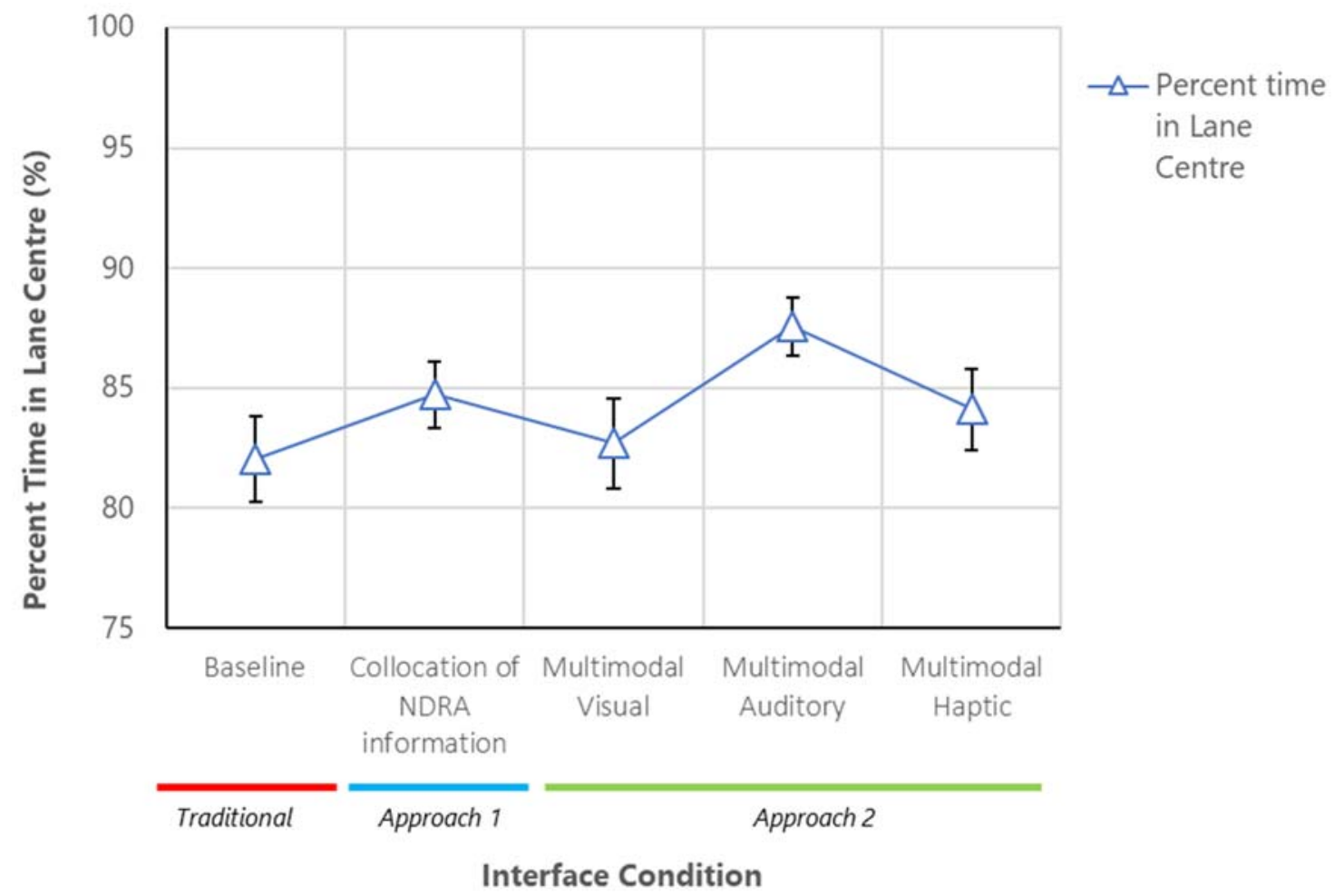

Figure 19 - Mean percent time following a vehicle during multitasking by interface condition

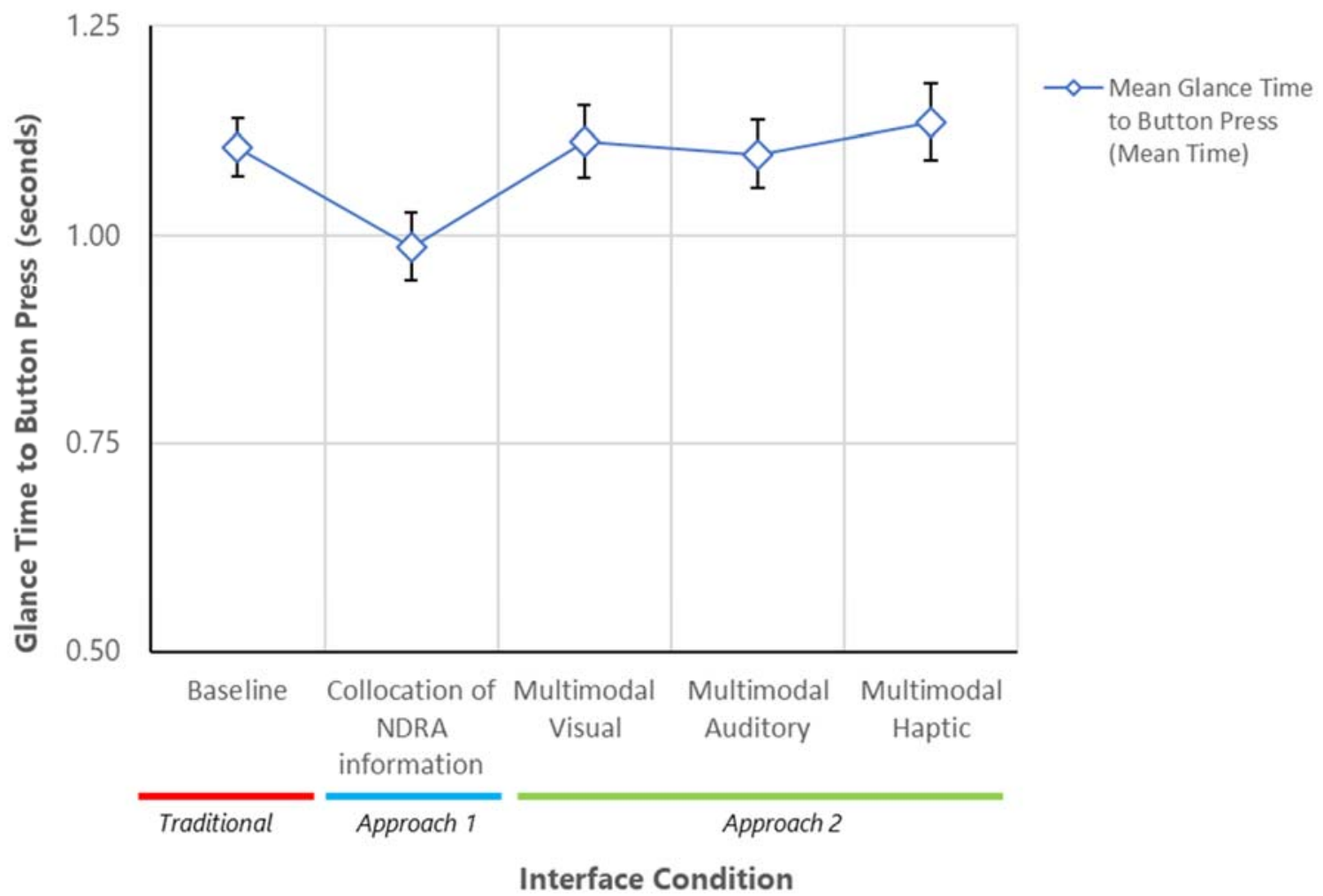

Figure 20 - Glance time to button press during multitasking by interface condition 


\section{Discussion}

\section{Attention Management}

The first result to discuss concerns Attention Management because of its implication on task performance. A higher mean AttenD value indicates more focus towards the road when compared to a lower mean AttenD value that indicates focus is being placed away from the road, which in this case meant the driver was focusing on the NDRA. Therefore, the AttenD value can be used to understand how the driver was distributing their visual attention around the vehicle. However. there is one caveat to this discussion, which is that the mean AttenD value is only indicative of how well the driver was managing attention, it doesn't indicate whether this led to successful task performance. The DRA and NDRA performance measures discussed later, confirm how the different attention management results impacted overall performance. The mean AttenD value, however, gives a useful indication of where attention was directed during the multitasking period.

The significant increase in mean AttenD value for the Collocation concept (Figure 17) suggests that drivers are using the NDRA information located in the HUD. As the eye tracker system cannot distinguish between focus on the road scene and HUD information, it is not possible to say for certain that this is the case. However, it can be assumed that if the driver was not using the NDRA information in the HUD that the mean AttenD value would have been comparable to that of the standard setup, which was not the case here (Figure 17). This means that instead of moving their attention away from the road to look at the centre screen, they were using the HUD instead to build their knowledge of the NDRA system. As predicted (Table 2), the Multimodal DRA Information concepts (Multimodal Visual, Multimodal Auditory and Multimodal Haptic) mean AttenD value were comparable with the Baseline because during these conditions the NDRA was not supported. Therefore, they still needed to 
glance away from the road when carrying out the NDRA which led to a lower mean AttenD value.

The Collocation concept appeared to help balance attention when multitasking (Figure 21). The proximity of the display relative to the road meant that a quick glance, requiring only eye-movement, was needed to stay aware of the NDRA. The Baseline condition display was further away from the road, requiring both head and eye movements (Stahl, 1999). VisualVisual task switching can be very efficient providing the information is located within a certain range (Wickens and Liu, 1988). This appears to be the case with respect to the Collocation condition. The location of the supporting information meant that drivers could be more strategic with when and for how long they needed to look away from the road based upon the demands of the task (Boot et al., 2009).

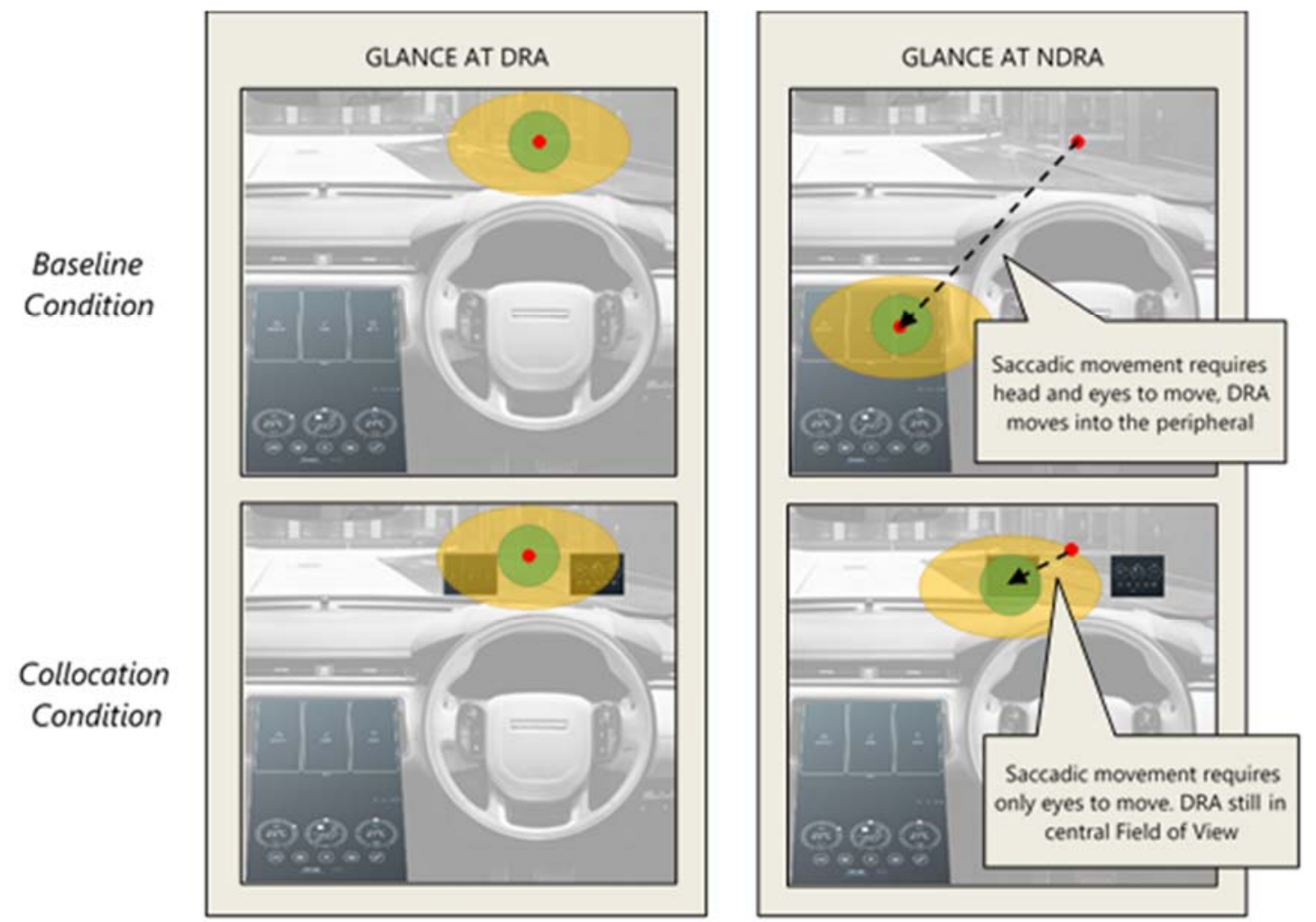

Figure 21 - Diagram of the angular relationship between display and eye movements for Collocation and Baseline conditions 
We chose to have the HUD neutrally coded which meant that when the driver looked at the HUD region, the buffer value stayed the same until they looked elsewhere. The mean AttenD value in this evaluation was sensitive to that decision. If the HUD had been coded negatively (as if the driver was looking away from the road), the significant differences between conditions may have disappeared. Equally, if the region had been coded positively (as if the driver was looking at the road), the significant results may have occurred in more than just the Collocation concept. This possibility raises one limitation with the AttenD method, which is that the HUD should be coded based upon what the driver was looking at. For example, if the participant is looking at DRA-based information, the buffer would increment, whilst when looking at NDRA based information, the buffer would decrement. Presently, no eye tracker can accurately measure the vergence angle of the eyes to determine whether a driver is observing the HUD or the environment beyond. If this were possible, we would be able to generate a more accurate representation. This is partially mitigated in our experiment by the location of our HUD in the periphery.

However, this presents a difficult issue regarding the contribution of HUD glances to the mean AttenD value. Certainly, there exists a difference between looking towards something and focusing upon it, therefore without this clarity an assumption needs to be made (Galpin et al., 2009; Simons and Ambinder, 2005). Another associated limitation is that whilst eyemovements are useful in the context of visual-manual type activities, there is a question over whether the same type of analysis could be useful for voice-based or purely cognitive activities. These types of activities will still generate knowledge or engage semantic processing in working memory in the same way visual-manual activities do, but not exhibit the same resulting eye movements. This should be a topic of future investigation. Notably, the placement of the Collocation concept in the periphery resulted in data that suggest it was used, and that it influenced driver interaction strategy. 


\section{Non-Driving Related Activity Response Time}

The small but significant reduction in time spent looking away from the road (Figure 20), for each button response suggests that the contextual cueing display was having the predicted effect. The Collocation concept produced a significantly faster response time than the Baseline condition meaning that the null hypothesis can be rejected (H1). This suggests that the extra information successfully primed the driver as to the next step in the task and was of no detriment to the DRA, as suggested by the task performance data (Figure 18 and Figure 19). The additional knowledge, given by the display, of the current NDRA state suggests that multitasking performance can be improved using an SA-based IVIS. Uncertainty with interface systems can impact response times (Dobres et al., 2015). The provision of a visual cue in the periphery of the field of view of the road ahead appeared to give drivers in this simulator study additional awareness such that when they did glance away from the road they could be more efficient with the glance. The size of the improvement found is relatively small, possibly because of the variety of visual-manual task types included, such as menu navigation and list manipulation (Figure 20). A more detailed investigation into the task types may uncover a differential effect and show where the Collocation concept is most effective.

Theoretically, it is worth considering the cognitive operational mechanisms at play. Does this effect make use of Working Memory, Long-Term Memory or a combination of both? If Working Memory is involved, the display will be perceived and stored in Short-Term Memory such that the correct button can be identified. Meaning that when they did look away from the road they could match the display to the one held in memory and thus easily locate the button. If Long-Term Memory is involved the display will simply cue the driver to the current state and hence the amount of time spent looking at the display may be lower. As the Attention Management results indicate a significant increase in the amount of time the driver 
spent looking at the HUD; the relatively small increase in task performance found, and because NDRAs are typically infrequently used, Working Memory is the most likely explanation. However, certain familiar tasks may implicate both Short- and Long-Term Memory, especially if the driver is able to carry out the task without the need to look away from the road. If Working Memory is implicated, care is needed to make sure that the amount of information is appropriate considering the capacity limitations (Baddeley, 2003; Wickens, 2008).

With the NDRA information being located head up, it is collocated with what is typically seen as the driving environment. In the context of SA-based design, this appears to conflict with conventional logic of separating out DRA and NDRA based information. Separation is common in design of the automotive environment for two reasons, one to keep the information away from obscuring the view of the road ahead, and secondly because designers tend to group controls by function (Marberger et al., 2004). However, by avoiding the central field of view and intentionally placing the information approximate to the road scene, the driver has a way of more strategically planning an interaction beforehand, thus providing them with a way of preparing for the next task step (St. John and Smallman, 2008).

Neither (Lauber et al., 2014; Weinberg et al., 2011), found task improvements equivalent to those seen in this setup. This may be because of the difficulty of realising virtual interaction with a display such as an HUD. Both approaches referenced, involved modified methods for how the user inputted to the system. Therefore, the approach used in the present experiment appeared to be a good compromise of consistency in terms of input but provided supplementary information to help the driver manage the complexity of in-vehicle multitasking. The key characteristic of the Collocation concept is that it appears to reduce the switching cost associated with multitasking (Monsell, 2003). 


\section{Lane Keeping}

For Percent Time spent in Lane Centre (PTLC, Figure 18), all conditions produced a high percentage of lane centre occupancy $(80 \%+)$, indicating that even when multitasking this was a priority for drivers. The significant improvement in PTLC for the Multimodal Auditory concept, when compared to the Baseline condition, suggests that auditory feedback achieved its intended function, allowing for the null hypothesis $(H 2)$ to be rejected. In this context, the advantage of the Multimodal Auditory concept was to provide a parallel channel of information in accordance with Multiple Resources Theory (Wickens, 2002; Wickens and Liu, 1988). The original intention was that the feedback may help the driver adjust the vehicle position whilst looking at the NDRA. However, when considering alongside the Attention Management result (Figure 17) what appears to have happened was that the auditory feedback triggered the driver to look back at the road before making an adjustment. The Attention Management result for the Multimodal Auditory concept shows an increase in the balance towards the roadway. This suggests that there was an increase in glancing towards the road when compared to the Baseline condition during multitasking. The lack of evidence to support the visually biased conditions (Collocation and Multimodal Visual) is unsurprising considering the time-critical nature of the feedback. This meant that the driver could easily miss the warning if they were focussed on the NDRA at the same time (Wittmann et al., 2006).

The PTLC findings are in agreement with (Suzuki, 2003) but in conflict with (Rossmeier et al., 2005). Suzuki and Jansson, (2003) found auditory warnings to cue visual attention back to the road so adjustments could be made after re-establishing the visual resource, rather than triggering drivers to make steering adjustments without looking. Conversely, Rossmeier et al., (2005) found the feedback triggered a steering response before visual input was available, but in a study that lasted much longer than the present study (approximately 5-6 hours). This 
does raise the question of how long would it take, if ever, for a driver to be able to use this feedback concurrently and achieve a skilled level of performance (Rasmussen, 1983). In the present study, not enough time was allowed for training and hence it would appear that drivers would need longer than the 45 minutes given here for performance with the system to endure (Dingus et al., 1997).

\section{Vehicle Headway}

Vehicle following when multitasking is a challenge because of the need to continually look back at the road. A reduction or increase in the percentage of time spent following a vehicle will indicate a change in behaviour by the driver. This would indicate whether they felt more (an increase) or less (a reduction) comfortable when following a vehicle when multitasking. For Percent Time Following a Vehicle (PTFV, Figure 19), no differences were observed in the PTFV condition when compared to the Baseline condition. For all conditions, the headway feedback did not reduce the amount of time the driver spent following a lead vehicle, in agreement with (Saffarian et al., 2013). However, a difference was observed between the Multimodal Haptic and Collocation concepts suggesting an interesting effect on overtaking behaviour resulting from the IVIS. This suggests that, in the case of the Multimodal Haptic concept, drivers were willing to spend more time following a vehicle than during the Collocation concept, where explicit Vehicle Headway feedback wasn't present. However, the additional head up time created by the HUD information led to a much shorter amount of time spent following. The additional feedback during the Multimodal Haptic concept may have led to a situation where the driver felt more comfortable in completing an NDRA with a vehicle present than during the Collocation concept. Figure 22 shows the potential impact of the different forms of feedback. This suggests that in the Multimodal Haptic concept drivers were happy to complete the NDRA in the knowledge that the 
feedback was present, before overtaking. In the Collocation concept, there may be two reasons why drivers could have preferred to overtake sooner. Firstly, the fact that the head was up more often meant that the lead vehicle was in view for longer; and secondly, because no support to monitor Vehicle Headway was given, leading to insecurity about the situation.

One interesting possibility based upon this finding is whether the support given stimulates the driver to engage to a greater extent with the unsupported activity. For example, the safety net of the haptic feedback meant that the drivers may have felt more comfortable focusing on the NDRA. The additional support for the NDRA in the Collocation concept appeared to result in increased motivation to deal with the overtaking procedure first. In this experiment what appears to happen is that the information provided to support task A, appears to have the effect of increasing focus on task B because it makes task A easier. This is backed up by the attention management results, whereby the Collocation concept gave rise to the greatest focus towards the road.

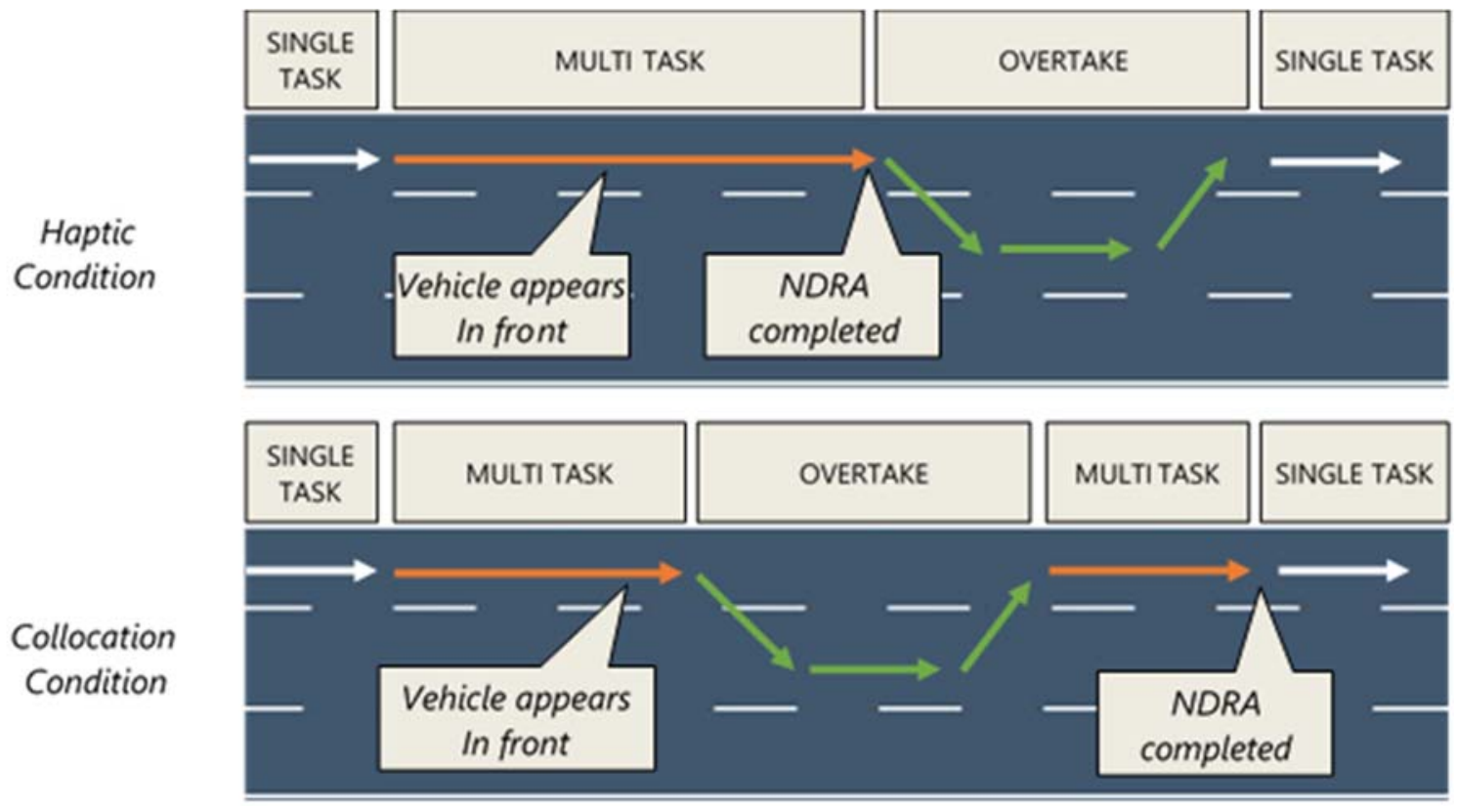

Figure 22 - Diagram showing the differences in overtaking behaviour between the haptic and collocation conditions. The white arrows indicate single task conditions, the orange arrows indicate multitasking periods, and the green arrows indicate overtaking periods. 


\section{Conclusion}

This research is focussed on the design of IVIS that harness the power of SA to improve task performance during in-vehicle multitasking. Two design approaches were investigated, the first was concerned with whether separating out information is at odds with multitasking and proposed the idea of Contextual Cueing of NDRA based information as a way of reducing the cost associated with task switching. The second attempted to utilise Multiple Resources Theory to provide DRA based information to help safeguard driving performance when an NDRA was active.

During this simulator study, the first approach (Collocation of NDRA Information) supported the user to carry out the NDRA as it significantly reduced the amount of time required to locate and operate a button when compared with a standard in-vehicle setup. While supporting the driver to carry out the target NDRA, this did not come at the cost of performance with the DRA, as shown by the comparable DRA performance to the standard condition. However, further research and analysis would need to look into whether this additional information could overload the driver with respect to more challenging DRA scenarios. The impact of collocating this information within the field of view of the road scene requires further investigation.

The second approach (Multimodal DRA Information) in the case of the Multimodal Auditory concept supported the driver with awareness of the position of the car in relation to the centre of the lane. An increase in time spent in the lane centre resulted during multitasking when compared to a standard in-vehicle setup with no feedback. The additional feedback did not appear to compromise performance for the NDRA. For a similar type of feedback for vehicle headway, no task performance differences occurred when compared with the baseline condition. However, differences in overtaking behaviour were found to be due to the 
emphasis (DRA or NDRA) of the vehicle headway feedback. Of the three types of feedback used for the second approach (Visual, Auditory and Haptic), the Multimodal Auditory concept appeared to provide the greatest support, however, this only appeared to prove more useful than a standard setup for Lane Keeping. None of the multimodal concepts improved performance for Vehicle Headway monitoring.

These results support the suggestion that IVIS designed to enhance driver awareness can provide task performance benefits during an in-vehicle multitasking situation. Two questions emerge. Firstly, whether these kinds of interfaces could work in tandem? Do the two systems that provided the most benefit (Multimodal Auditory and the Collocation concept), provide more benefit when applied together? Or does the additional complexity of combining such information lead to negative effects? For example, as resulting from information overload or cross-modal interference (Spence, 2011; Sperling and Dosher, 1986). The second question raised is whether these experimental findings; under controlled laboratory settings, could be replicated in the real world? Does the translation of this IVIS into a real vehicle, with all of the additional noise factors, complexities, and risks mean that the benefits found are nullified? It is clear that future research will need to establish this before claiming real world benefits.

Consider the driver who, having been restricted from using their IVIS, looks away from the road to reach for their smartphone. Or, the driver who, having determined that their semiautomated driving system is not leaving the lane, begins engaging with their social media. Both may be served by well-engineered systems designed to protect their lives, and both may be less safe due to the interaction of the design decisions with the risk of FOMO. Regardless of legislation; what the manual states, and training, it seems likely that these behaviours persist on roadways worldwide. Constrained Design and Vehicle Automation have a role to 
play but ultimately neither is addressing effectively the crucial problem of distraction on the roadway. The theoretical approach described in (Skrypchuk et al., 2019) and the experimental evidence presented in this paper, outline the potential for SA-based Unconstrained Design to enhance performance in an automotive multitasking situation. This may lead to IVIS design that can support a driver to multitask in the vehicle in a safe and efficient manner. A design that fully incorporates the implications of doing so in a complex environment. These findings suggest a new and exciting path forward to reduced distraction and enhanced automotive safety through Unconstrained Design.

\section{Acknowledgements}

This research is funded by Jaguar Land Rover Research Department in collaboration with the Centre for Advanced Photonics and Electronics (CAPE) and the Engineering Design Centre at Cambridge University.

\section{References}

Altmann, E.M., 2004. The Preparation Effect in Task Switching: Carryover of SOA. Mem. Cognit. 32, 153-163. https://doi.org/10.3758/BF03195828

Altmann, E.M., Trafton, J.G., 2002. Memory for Goals: An Activation-based Model. Cogn. Sci. 26, 39-83. https://doi.org/10.1207/s15516709cog2601_2

Angell, L.S., Perez, M., Soccolich, S., 2015. Identification of Cognitive Load in Naturalistic Driving, Virginia Tech Transportation Institute.

Baddeley, A.D., 2003. Working Memory: Looking Back and Looking Forward. Nat. Rev. Neurosci. 4, 829-39. https://doi.org/10.1038/nrn1201

Bellotti, F., Berta, R., De Gloria, A., Margarone, M., 2002. Using 3D Sound to Improve the 
Effectiveness of the Advanced Driver Assistance Systems. Pers. Ubiquitous Comput. 6, 155-163. https://doi.org/10.1007/s007790200016

Bennett, K.B., Nagy, A.L., Flach, J.M., 2012. Visual Displays, in: Handbook of Human Factors and Ergonomics. John Wiley \& Sons, Inc., Hoboken, NJ, USA, pp. 1177-1208. https://doi.org/10.1002/9781118131350.ch42

Bhise, V.D., 2016. Ergonomics in the Automotive Design Process. CRC Press. https://doi.org/10.1201/b11237

Biondi, F., Rossi, R., Gastaldi, M., Mulatti, C., 2014. Beeping ADAS: Reflexive Effect on Drivers' Behavior. Transp. Res. Part F Traffic Psychol. Behav. 25, 27-33. https://doi.org/10.1016/j.trf.2014.04.020

Boot, W.R., Becic, E., Kramer, A.F., 2009. Stable individual differences in search strategy?: The effect of task demands and motivational factors on scanning strategy in visual search. J. Vis. 9, 7-7. https://doi.org/10.1167/9.3.7

Borenstein, D., 1998. Towards a Practical Method to Validate Decision Support Systems. Decis. Support Syst. 23, 227-239. https://doi.org/10.1016/S0167-9236(98)00046-3

Brumby, D.P., Salvucci, D.D., Howes, A., 2007. A cognitive constraint model of dual-task trade-offs in a highly dynamic driving task, in: Proceedings of the SIGCHI Conference on Human Factors in Computing Systems - CHI '07. ACM Press, New York, New York, USA, p. 233. https://doi.org/10.1145/1240624.1240664

Burghardt, S., Weig, F., Choi, S., 2017. Mobility trends: What's ahead for automotive [WWW Document]. McKinsey Co. URL https://www.mckinsey.com/industries/semiconductors/our-insights/mobility-trends- 
whats-ahead-for-automotive-semiconductors

Castells, M., 1997. An introduction to the information age. City 2, 6-16. https://doi.org/10.1080/13604819708900050

Charissis, V., Naef, M., 2007. Evaluation of Prototype Automotive Head-Up Display Interface: Testing Driver's Focusing Ability through a VR Simulation, in: 2007 IEEE Intelligent Vehicles Symposium. IEEE, pp. 560-565. https://doi.org/10.1109/IVS.2007.4290174

Chiappe, D., Strybel, T.Z., Vu, K.P.L., 2015. A Situated Approach to the Understanding of Dynamic Situations. J. Cogn. Eng. Decis. Mak. 9, 33-43. https://doi.org/10.1177/1555343414559053

Chun, M.M., 2000. Contextual cueing of visual attention. Trends Cogn. Sci. 4, 170-178. https://doi.org/10.1016/S1364-6613(00)01476-5

Dass, D.E., Uyttendaele, A., Terken, J., 2013. Haptic in-seat feedback for lane departure warning, in: Proceedings of the 5th International Conference on Automotive User Interfaces and Interactive Vehicular Applications - AutomotiveUI '13. ACM Press, New York, New York, USA, pp. 258-261. https://doi.org/10.1145/2516540.2516574

Dingus, T.A., McGehee, D. V., Manakkal, N., Jahns, S.K., Carney, C., Hankey, J.M., 1997. Human Factors Field Evaluation of Automotive Headway Maintenance/Collision Warning Devices. Hum. Factors J. Hum. Factors Ergon. Soc. 39, 216-229. https://doi.org/10.1518/001872097778543930

Dobres, J., Reimer, B., Parikhal, L., Wean, E., Chahine, N., 2015. The Incredible Shrinking Letter: How Font Size Affects the Legibility of Text Viewed in Brief Glances, in: 8th 
International Driving Symposium on Human Factors in Driver Assessment, Training and Vehicle Design. Salt Lake City, UT, pp. 429-435.

Dowell, S.R., Foyle, D.C., Hooey, B.L., Williams, J.L., 2012. The Effect of Visual Location on Cognitive Tunneling with Superimposed Hud Symbology. Proc. Hum. Factors Ergon. Soc. Annu. Meet. 46, 121-125. https://doi.org/10.1177/154193120204600125

Driver Focus-Telematics Working Group, 2003. Statement of Principles, Criteria and Verification Procedures on Driver Interactions with Advanced In-Vehicle Information and Communication Systems. Washington, DC: Alliance of Automobile Manufacturers.

Endsley, M.R., Bolte, B., Jones, D.G., 2003. Designing for Situation Awareness: An Approach to User-Centred Design, 2nd ed. CRC Press. https://doi.org/10.1201/9780203485088

European Commission, 2006. Update of the European Statement of Principles on human machine interface.

Finley, J.R., Benjamin, A.S., McCarley, J.S., 2014. Metacognition of multitasking: How well do we predict the costs of divided attention? J. Exp. Psychol. Appl. 20, 158-165. https://doi.org/10.1037/xap0000010

Galpin, A., Underwood, G., Crundall, D., 2009. Change blindness in driving scenes. Transp. Res. Part F Traffic Psychol. Behav. 12, 179-185. https://doi.org/10.1016/j.trf.2008.11.002

Gartenberg, D., Breslow, L., McCurry, J.M., Trafton, J.G., 2014. Situation Awareness Recovery. Hum. Factors J. Hum. Factors Ergon. Soc. 56, 710-727. https://doi.org/10.1177/0018720813506223 
Golding, J.F., 1998. Motion sickness susceptibility questionnaire revised and its relationship to other forms of sickness. Brain Res. Bull. 47, 507-516. https://doi.org/10.1016/S03619230(98)00091-4

Gonzalez, C., Lewis, B.A., Roberts, D.M., Pratt, S.M., Baldwin, C.L., 2012. Perceived Urgency and Annoyance of Auditory Alerts in a Driving Context. Proc. Hum. Factors Ergon. Soc. Annu. Meet. 56, 1684-1687. https://doi.org/10.1177/1071181312561337

Gordon, F.R., Flavell, J.H., 1977. The Development of Intuitions about Cognitive Cueing. Child Dev. 48, 1027. https://doi.org/10.2307/1128355

Greenlee, E.T., DeLucia, P.R., Newton, D.C., 2018. Driver Vigilance in Automated Vehicles: Hazard Detection Failures Are a Matter of Time. Hum. Factors. https://doi.org/10.1177/0018720818761711

Gugerty, L.J., 1997. Situation awareness during driving: Explicit and implicit knowledge in dynamic spatial memory. J. Exp. Psychol. Appl. 3, 42-66. https://doi.org/10.1037/1076898X.3.1.42

Hancock, P.A., Lesch, M., Simmons, L., 2003. The distraction effects of phone use during a crucial driving maneuver. Accid. Anal. Prev. 35, 501-514. https://doi.org/10.1016/S0001-4575(02)00028-3

Hardiess, G., Gillner, S., Mallot, H.A., 2008. Head and eye movements and the role of memory limitations in a visual search paradigm. J. Vis. $8,7$. https://doi.org/10.1167/8.1.7

Hayes, K.J., Thompson, R., Hayes, C., 1953. Discrimination learning set in chimpanzees. J. Comp. Physiol. Psychol. 46, 99-104. https://doi.org/10.1037/h0056424 
Ho, C., Gray, R., Spence, C., 2014. Reorienting Driver Attention with Dynamic Tactile Cues. IEEE Trans. Haptics 7, 86-94. https://doi.org/10.1109/TOH.2013.62

Horowitz, A.D., Dingus, T.A., 1992. Warning Signal Design: A Key Human Factors Issue in an In-Vehicle Front-To-Rear-End Collision Warning System. Proc. Hum. Factors Ergon. Soc. Annu. Meet. 36, 1011-1013. https://doi.org/10.1177/154193129203601320

International Transport Forum, 2017. ITF Transport Outlook 2017. https://doi.org/10.1787/9789282107782-en

JAMA, 2004. Guideline for In-Vehicle Display Systems.

Jamson, H.A., Merat, N., 2005. Surrogate in-vehicle information systems and driver behaviour: Effects of visual and cognitive load in simulated rural driving. Transp. Res. Part F Traffic Psychol. Behav. 8, 79-96. https://doi.org/10.1016/j.trf.2005.04.002

Jarmasz, J., Herdman, C.M., Johannsdottir, K.R., 2005. Object-based attention and cognitive tunneling. J. Exp. Psychol. Appl. 11, 3-12. https://doi.org/10.1037/1076-898X.11.1.3

Ji, Y.G., Lee, K., Hwang, W., 2011. Haptic perceptions in the vehicle seat. Hum. Factors Ergon. Manuf. Serv. Ind. 21, 305-325. https://doi.org/10.1002/hfm.20235

Kim, H., Wu, X., Gabbard, J.L., Polys, N.F., 2013. Exploring head-up augmented reality interfaces for crash warning systems, in: Proceedings of the 5th International Conference on Automotive User Interfaces and Interactive Vehicular Applications - AutomotiveUI '13. ACM Press, New York, New York, USA, pp. 224-227. https://doi.org/10.1145/2516540.2516566

Kircher, K., Ahlstrom, C., 2017. Minimum Required Attention: A Human-Centered Approach to Driver Inattention. Hum. Factors J. Hum. Factors Ergon. Soc. 59, 471-484. 
https://doi.org/10.1177/0018720816672756

Kircher, K., Ahlstrom, C., 2009. Issues related to the driver distraction detection algorithm AttenD. 1st Int. Conf. Driv. Distraction Ina. 1-15.

Lang, A., Chrzan, J., 2015. Media Multitasking: Good, Bad, or Ugly? Ann. Int. Commun. Assoc. 39, 99-128. https://doi.org/10.1080/23808985.2015.11679173

Langdon, P.M., Lewis, T., Clarkson, P.J., 2010. Prior experience in the use of domestic product interfaces. Univers. Access Inf. Soc. 9, 209-225.

https://doi.org/10.1007/s10209-009-0169-9

Lauber, F., Follmann, A., Butz, A., 2014. What you see is what you touch, in: Proceedings of the 2014 Conference on Designing Interactive Systems - DIS '14. ACM Press, New York, New York, USA, pp. 171-180. https://doi.org/10.1145/2598510.2598521

Lee, J.D., McGehee, D. V., Brown, T.L., Reyes, M.L., 2002. Collision Warning Timing, Driver Distraction, and Driver Response to Imminent Rear-End Collisions in a HighFidelity Driving Simulator. Hum. Factors J. Hum. Factors Ergon. Soc. 44, 314-334. https://doi.org/10.1518/0018720024497844

Lee, J.D., Young, K.L., Regan, M.A., 2008. Defining driver distraction, in: Regan, M.A., Lee, J.D., Young, K.L. (Ed.), Driver Distraction: Theory, Effects, and Mitigation. CRC Press Taylor \& Francis Group, Boca Raton, FL, USA, pp. 31-40.

Lee, T.B., 2018. Waymo announces 7 million miles of testing, putting it far ahead of rivals [WWW Document]. arstechnica.com. URL https://arstechnica.com/cars/2018/06/waymo-announces-7-million-miles-of-testingputting-it-far-ahead-of-rivals/ 
Litman, T., 2014. Autonomous Vehicle Implementation Predictions: Implications for Transport Planning. Transp. Res. Board Annu. Meet. 36-42.

Liu, Y.C., 2003. Effects of using head-up display in automobile context on attention demand and driving performance. Displays 24, 157-165. https://doi.org/10.1016/j.displa.2004.01.001

Marberger, C., Dangelmaier, M., Widlroitber, H., Bekiaris, E., 2004. User centred HMI development in the AWAKE - project, in: IEEE International Conference on Systems, Man and Cybernetics. pp. 170-175.

Meng, F., Spence, C., 2015. Tactile warning signals for in-vehicle systems. Accid. Anal. Prev. 75, 333-346. https://doi.org/10.1016/j.aap.2014.12.013

Mohr, D., Muller, N., Krieg, A., Gao, P., Kaas, H.-W., Krieger, A., Hensley, R., 2013. The road to 2020 and beyond: What's driving the global automotive industry?, McKinsey \& Company.

Monsell, S., 2003. Task switching. Trends Cogn. Sci. 7, 134-140. https://doi.org/10.1016/S1364-6613(03)00028-7

Nees, M.A., Walker, B.N., 2011. Auditory Displays for In-Vehicle Technologies. Rev. Hum. Factors Ergon. 7, 58-99. https://doi.org/10.1177/1557234X11410396

NHTSA, 2014. Visual-Manual NHTSA Driver Distraction Guidelines for In-Vehicle Electronic Devices, Federal Register: Docket No. NHTSA-2010-0053. https://doi.org/NHTSA-2010-0053

OICA, 2018. New PC Registrations or Sales 2017 [WWW Document]. Organ. Int. des Constr. d'Automobiles. URL http://www.oica.net/wp-content/uploads/Sales-Passenger- 
cars-2017.pdf

OICA, 2015. Recommended OICA Worldwide Distraction Guideline Policy Position.

Parnell, K.J., Stanton, N.A., Plant, K.L., 2018. What technologies do people engage with while driving and why? Accid. Anal. Prev. 111, 222-237. https://doi.org/10.1016/j.aap.2017.12.004

Peng, Y., Boyle, L.N., Hallmark, S.L., 2013. Driver's lane keeping ability with eyes off road: Insights from a naturalistic study. Accid. Anal. Prev. 50, 628-634. https://doi.org/10.1016/j.aap.2012.06.013

Polson, P.G., Anderson, J.R., Bower, G.H., 1975. Human Associative Memory. Am. J. Psychol. 88, 131. https://doi.org/10.2307/1421672

Przybylski, A.K., Murayama, K., DeHaan, C.R., Gladwell, V., 2013. Motivational, emotional, and behavioral correlates of fear of missing out. Comput. Human Behav. 29, 1841-1848. https://doi.org/10.1016/j.chb.2013.02.014

Rasmussen, J., 1983. Skills, rules, and knowledge; signals, signs, and symbols, and other distinctions in human performance models. IEEE Trans. Syst. Man. Cybern. SMC-13, 257-266. https://doi.org/10.1109/TSMC.1983.6313160

Regan, M.A., Hallett, C., Gordon, C.P., 2011. Driver distraction and driver inattention: Definition, relationship and taxonomy. Accid. Anal. Prev. 43, 1771-1781. https://doi.org/10.1016/j.aap.2011.04.008

Regan, M.A., Young, K.L., Lee, J.D., Gordon, C., 2008. Sources of Driver Distraction, in: Driver Distraction. CRC Press, pp. 249-279. https://doi.org/10.1201/9781420007497.pt5 
Riener, A., 2011. Information injection below conscious awareness: Potential of sensory channels, in: 3rd International Conference on Automotive User Interfaces and Interactive Vehicular Applications (AutomotiveUI 2011),

Rogé, J., Ndiaye, D., Vienne, F., 2014. Useful visual field training: A way to improve elderly car drivers' ability to detect vulnerable road users. Transp. Res. Part F Traffic Psychol. Behav. 26, 246-257. https://doi.org/10.1016/j.trf.2014.08.005

Rossmeier, M., Grabsch, H., Rimini-Doering, M., 2005. Blind flight: Do auditory lane departure warnings attract attention or actually guide action? Proc. 11th Int. Conf. Audit. Disp. 43-48.

Rudisill, T.M., Zhu, M., 2016. Who actually receives cell phone use while driving citations and how much are these laws enforced among states? A descriptive, cross-sectional study. BMJ Open 6. https://doi.org/10.1136/bmjopen-2016-011381

SAE International, 2018. Taxonomy and Definitions for Terms Related to Driving Automation Systems for On-Road Motor Vehicles, J3016 Standards.

Saffarian, M., de Winter, J.C.F., Happee, R., 2013. Enhancing Driver Car-Following Performance with a Distance and Acceleration Display. IEEE Trans. Human-Machine Syst. 43, 8-16. https://doi.org/10.1109/TSMCA.2012.2207105

Sanbonmatsu, D.M., Strayer, D.L., Medeiros-Ward, N., Watson, J.M., 2013. Who MultiTasks and Why? Multi-Tasking Ability, Perceived Multi-Tasking Ability, Impulsivity, and Sensation Seeking. PLoS One 8, e54402. https://doi.org/10.1371/journal.pone.0054402

Seppelt, B.D., Lee, J.D., 2007. Making adaptive cruise control (ACC) limits visible. Int. J. 
Hum. Comput. Stud. 65, 192-205. https://doi.org/10.1016/j.ijhcs.2006.10.001

Simons, D.J., Ambinder, M.S., 2005. Change Blindness. Curr. Dir. Psychol. Sci. 14, 44-48. https://doi.org/10.1111/j.0963-7214.2005.00332.x

Skrypchuk, L., Langdon, P.M., Sawyer, B.D., Mouzakitis, A., Clarkson, P.J., 2019. Enabling multitasking by designing for situation awareness within the vehicle environment. Theor. Issues Ergon. Sci. 20, 105-128. https://doi.org/10.1080/1463922X.2018.1485984

Sojourner, R.J., Antin, J.F., 1990. The effects of a simulated head-up display speedometer on perceptual tasks performance. Hum. Factors. https://doi.org/10.1177/001872089003200306

Spence, C., 2011. Crossmodal correspondences: A tutorial review. Attention, Perception, Psychophys. 73, 971-995. https://doi.org/10.3758/s13414-010-0073-7

Sperling, G., Dosher, A.D., 1986. Strategy and optimization in human information processing. Handb. $\{\mathrm{P}\}$ erception $\{\mathrm{P}\}$ erformance 1, 2.1-2.65.

St. John, M., Smallman, H.S., 2008. Staying Up to Speed: Four Design Principles for Maintaining and Recovering Situation Awareness. J. Cogn. Eng. Decis. Mak. 2, 118 139. https://doi.org/10.1518/155534308X284408

Stahl, J.S., 1999. Amplitude of human head movements associated with horizontal saccades. Exp. Brain Res. 126, 41-54. https://doi.org/10.1007/s002210050715

Suzuki, K., 2003. An analysis of driver's steering behaviour during auditory or haptic warnings for the designing of lane departure warning system. JSAE Rev. 24, 65-70. https://doi.org/10.1016/S0389-4304(02)00247-3 
Vicente, K.J., 2002. Ecological Interface Design: Progress and Challenges. Hum. Factors J. Hum. Factors Ergon. Soc. 44, 62-78. https://doi.org/10.1518/0018720024494829

Weinberg, G., Harsham, B., Medenica, Z., 2011. Evaluating the usability of a head-up display for selection from choice lists in cars, in: Proceedings of the 3rd International Conference on Automotive User Interfaces and Interactive Vehicular Applications AutomotiveUI '11. ACM Press, New York, New York, USA, p. 39. https://doi.org/10.1145/2381416.2381423

Wickens, C.D., 2008. Multiple Resources and Mental Workload. Hum. Factors J. Hum. Factors Ergon. Soc. 50, 449-455. https://doi.org/10.1518/001872008X288394

Wickens, C.D., 2002. Multiple resources and performance prediction. Theor. Issues Ergon. Sci. 3, 159-177. https://doi.org/10.1080/14639220210123806

Wickens, C.D., 1993. Cognitive Factors in Display Design. J. Washingt. Acad. Sci. https://doi.org/10.2307/24531392

Wickens, C.D., Liu, Y., 1988. Codes and Modalities in Multiple Resources: A Success and a Qualification. Hum. Factors J. Hum. Factors Ergon. Soc. 30, 599-616. https://doi.org/10.1177/001872088803000505

Wittmann, M., Kiss, M., Gugg, P., Steffen, A., Fink, M., Pöppel, E., Kamiya, H., 2006. Effects of display position of a visual in-vehicle task on simulated driving. Appl. Ergon. 37, 187-199. https://doi.org/10.1016/j.apergo.2005.06.002

Wolfe, B., Sawyer, B.D., Kosovicheva, A., Reimer, B., Rosenholtz, R., 2019. Detection of Brake Lights While Distracted: Separating Peripheral Vision from Cognitive Load. Attention, Perception, Psychophys. In Press. 
Yanko, M.R., Spalek, T.M., 2014. Driving With the Wandering Mind. Hum. Factors J. Hum. Factors Ergon. Soc. 56, 260-269. https://doi.org/10.1177/0018720813495280

Yap, J.Y., Lim, S.W.H., 2013. Media multitasking predicts unitary versus splitting visual focal attention. J. Cogn. Psychol. 25, 889-902. https://doi.org/10.1080/20445911.2013.835315

Yeh, M., Merlo, J.L., Wickens, C.D., Brandenburg, D.L., 2003. Head Up versus Head Down: The Costs of Imprecision, Unreliability, and Visual Clutter on Cue Effectiveness for Display Signaling. Hum. Factors. https://doi.org/10.1518/hfes.45.3.390.27249 